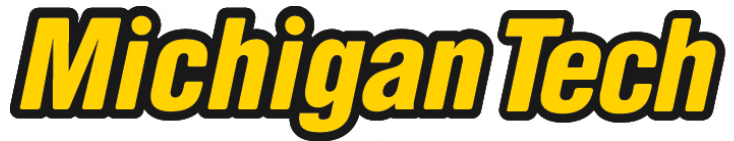 \\ Michigan Technological University Create the Future Digital Commons @ Michigan Tech
}

2012

\section{Assessment of water and sanitation infrastructure at primary schools in Rakai District, Uganda}

Colin M. Casey

Michigan Technological University

Follow this and additional works at: https://digitalcommons.mtu.edu/etds

Part of the Civil and Environmental Engineering Commons

Copyright 2012 Colin M. Casey

\section{Recommended Citation}

Casey, Colin M., "Assessment of water and sanitation infrastructure at primary schools in Rakai District, Uganda", Master's report, Michigan Technological University, 2012.

https://doi.org/10.37099/mtu.dc.etds/500

Follow this and additional works at: https://digitalcommons.mtu.edu/etds

Part of the Civil and Environmental Engineering Commons 


\title{
AN ASSESSMENT OF WATER AND SANITATION INFRASTRUCTURE AT PRIMARY SCHOOLS IN RAKAI DISTRICT, UGANDA
}

\section{By}

\author{
Colin M. Casey
}

\begin{abstract}
A REPORT
Submitted in partial fulfillment of the requirements for the degree of MASTER OF SCIENCE
\end{abstract}

Civil Engineering

MICHIGAN TECHNOLOGICAL UNIVERSITY

2012

(C) 2012 Colin M. Casey 
This report, "An Assessment of Water and Sanitation Infrastructure at Primary Schools in Rakai District, Uganda," is hereby approved in partial fulfillment of the requirements for the degree of Master of Science in Civil Engineering.

DEPARTMENT:

Civil and Environmental Engineering

Signatures:

Report Advisor:

Dr. Kurt Paterson

Department Chair:

Dr. David Hand

Date: 


\section{TABLE OF CONTENTS}

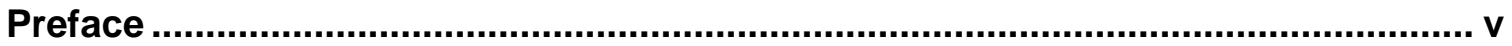

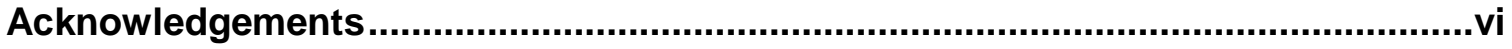

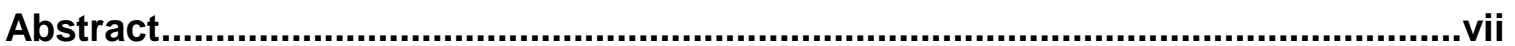

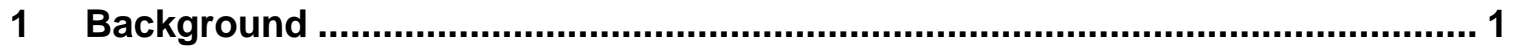

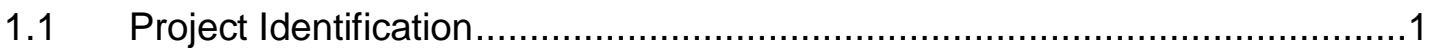

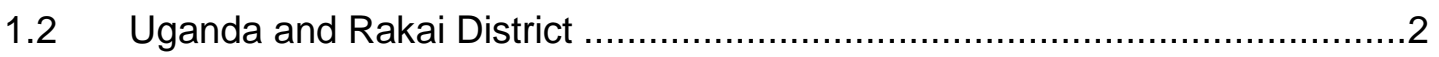

1.3 Water and Sanitation Statistics ........................................................ 5

1.4 Primary School Observation and Policy ..............................................

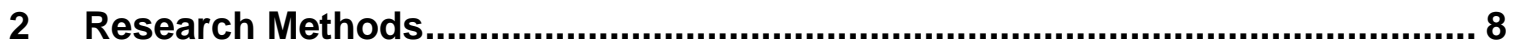

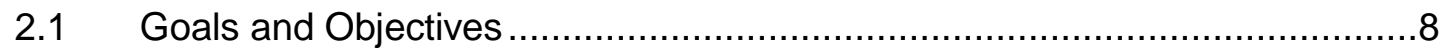

2.2 School Interviews ..........................................................................

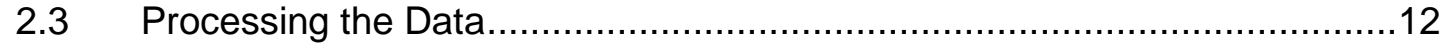

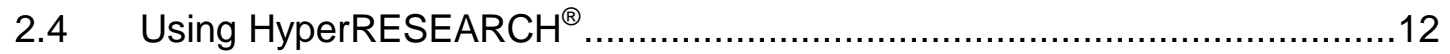

2.5 FEWS NET Rainfall Estimates .....................................................13

3 Results and Observation ..............................................................................14

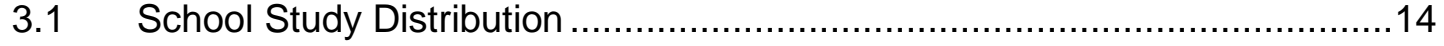

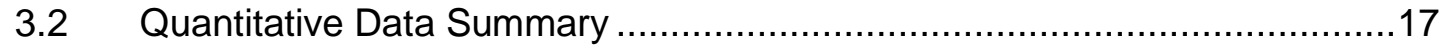

3.2.1 Water Sources, Distance, and Use .....................................17

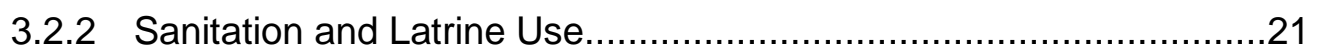

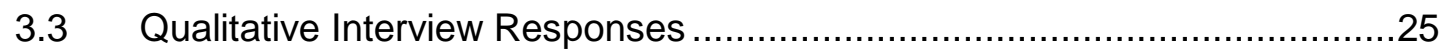

3.3.1 Water Successes, Challenges, and Improvements ......................26

3.3.2 Sanitation Successes, Challenges, and Improvements..................29

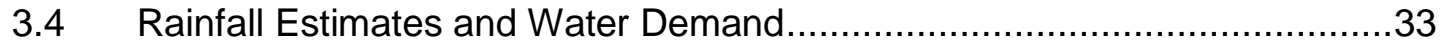

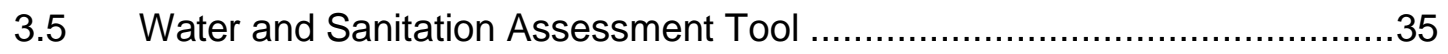

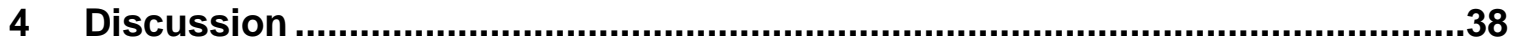

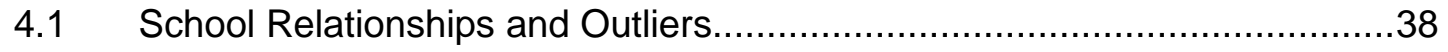

4.2 Observed WASH Technologies................................................ 40

4.2.1 Common Water Sources .....................................................40

4.2.2 Common Latrine Sources ..................................................42

4.2.3 Hygiene and Hand-washing ...............................................44 


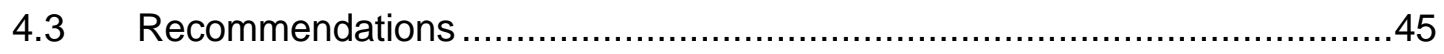

4.3.1 Prioritizing Water and Sanitation...........................................45

4.3.2 Addressing Rainwater Collection .............................................45

4.3.3 Assessment Tool Variables ..................................................4

5 Conclusions...................................................................................................48

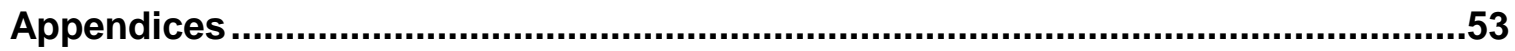

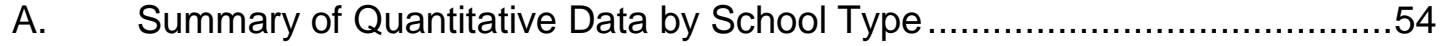

B. Water and Sanitation Assessment Tool Quadrant Summary .....................57

C. Interview Guide and Response Sample .........................................59

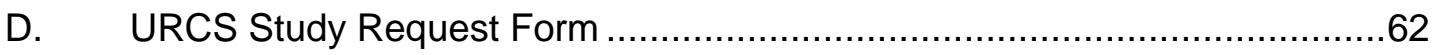

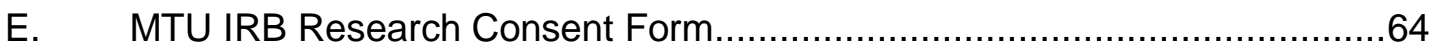

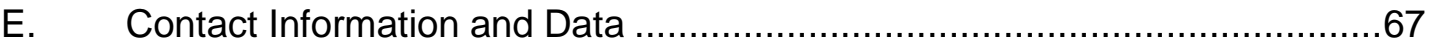




\section{LIST OF FIGURES}

Figure 1.1: Photo of Rakai Town Council, Rakai District, Uganda. (Photo by author).... 3

Figure 1.2: Map of Uganda with location of study in Rakai District outlined. Map reproduced from www.mapsof.net (6).

Figure 1.3: Percent of population with sustainable access to improved water sources and sanitation. World and Uganda statistics (2006 UGANDA DEMO) compared to regional Rakai District data (RAKAI MDG 2010 REPORT)..................... 6

Figure 2.1: Research flow diagram for the assessment of primary schools' water and sanitation condition.

Figure 3.1: : Map from the 2010 Millennium Development Report Update (4) of Rakai District with population per county provided by the Uganda Population and Housing Census for Rakai District, Planning Department (2002).

Figure 3.2: Identifying school water sources, average distance to sources, and percentage of use by school type.

Figure 3.3: Schools' estimated average daily water use value per pupil. .21

Figure 3.4: School latrine sources and percentage of use by school type. .22

Figure 3.5: Schools' calculated pupil to latrine stance ratios.

Figure 3.6: Interview responses concerning latrine use and hygiene. .25

Figure 3.7: Interview responses concerning water successes by school type. .26

Figure 3.8: Interview responses concerning water challenges by school type. .27

Figure 3.9: Interview responses concerning water improvements by school type. .28

Figure 3.10: Interview responses concerning sanitation successes by school type .29 
Figure 3.11: Interview responses concerning sanitation challenges by school type.

Figure 3.12: Interview responses concerning sanitation improvements by school type..32

3.13: Rakai District rainfall estimates (2000-2012) and school water demand plotted to determine a school's required storage volume for the largest water deficit experienced in one school year....

Figure 3.14: Identifying relationships among Rakai District primary schools using the Water and Sanitation Assessment Tool.

\section{LIST OF TABLES}

Table 3.1: Identifying schools sampled by school type and location in Rakai District.....15

Table 3.2: Estimated daily water use values per school by school type.

Table 3.3: Estimated daily water use values per pupil by school type. Author's use a recommended daily water use value of 2 L/day per pupil.

Table 3.4: Latrine stance quantities by school type .23

Table 3.5: Pupil to latrine stance ratios by school type. 


\section{Preface}

You are most welcome... so the saying goes in Uganda. Visitors to the country hear this when arriving to a Ugandan home, family celebration, or meeting. After two years of living in Uganda, I did feel most welcome, and am now excited to share my story about my time there.

As a Peace Corps Masters International student from the Michigan Technological University Department of Civil and Environmental Engineering, I was given an opportunity to work in Uganda with the Uganda Red Cross Society as a Water and Sanitation Engineer from August 2009 to October 2011. After an initial 10-week period living with a Ugandan host family and completing language, cross cultural, medical, technical, and safety and security training, I was placed alongside 100 other Peace Corps volunteers in the country to help develop the capacity of local Ugandan communities.

One of my goals as a volunteer-engineer was to find sustainable solutions for water and sanitation improvement projects utilizing local resources and people. I believed using local knowledge and intuition would be the most appropriate way to help improve people's well-being. I spent two years living in a small rural community learning from those around me while sharing knowledge and experience to those who were interested. I came to the program open minded and excited to work with community members, youth groups, women associations, church organizations, schools, non-profit organizations, and local government offices to help improve the region I lived in.

Throughout my two years in Uganda, I recorded work experiences with my University committee members through email, pictures, and quarterly reports. Quarterly reports were written to recognize achievements, challenges, and research ideas I had as a volunteer in the country. In this study, I build upon these reports to highlight my findings of an assessment of water and sanitation infrastructure at both government and private primary schools in Rakai District, Uganda. 


\section{Acknowledgements}

This assessment was completed by myself and close friend and colleague, Ssembatya Joseph. Without Joseph's help, wisdom, and friendship, I would have not been able to complete this work. Over the two years, Joseph worked closely with the staff at the Uganda Red Cross Society, Rakai Branch, on a voluntary basis without consistent pay. At the age of only 23, Joseph's volunteer spirit and motivation to learn and help others was unparallel. I would like to recognize our members from the Uganda Red Cross Society, and my close friends and colleagues at Peace Corps Uganda, the Rakai District government, and the Rakai community for their warm welcoming, mentoring, and encouragement. I would like to thank the schools we visited during this study and the information teachers and directors were able to share with us. Also to my family and friends who supported me throughout my Peace Corps service and came to visit on several occasions. To my colleagues and professors at the Michigan Technological University, most especially my Advisor Dr. Kurtis Paterson and committee members David Watkins and Kari Henquinet, who maintained interest in my work and provided insightful feedback when I needed it most. Webale nnyo bakwano bange! Thank you all very much my friends! 


\begin{abstract}
"Addressing water problems will help improve sanitation." This relationship identified by a primary school teacher in Rakai District, Uganda, was a key component in understanding how water and sanitation technologies interact and how identified successes, challenges, and improvements would enhance schools' water and sanitation condition. In this study, researchers and Ugandan counterparts visited 49 primary schools in Rakai District to assess the existing water and sanitation infrastructure of government and private schools. Researchers were specifically interested in learning which technologies were being used and why they were working or not. Through the development of a unique water and sanitation assessment tool, schools have been placed in to four relationship quadrants to rate existing water and latrine use standards. Recommendations including improved rainwater use and sanitation through composting have been offered to schools sampled.
\end{abstract}




\section{Background}

\subsection{Project Identification}

The issue of water and sanitation coverage in Ugandan primary schools came about early in the author's Peace Corps service. While working as a water and sanitation engineer with the Uganda Red Cross Society, the author made many visits to local primary schools where he observed water and sanitation practices. Discussions with local school teachers helped the author relate to challenges these schools faced. A complete study of water and sanitation infrastructure in primary schools came to being only after understanding coverage gaps and their contributing factors.

From October 2009 to 2011, the author lived and worked with the Uganda Red Cross Society, Rakai Branch in Rakai Town Council, Rakai District, Uganda. His role with the Red Cross was to address and identify resources in order to improve local water and sanitation conditions. Though the branch had no funding to implement water or sanitation projects, the author worked closely with his Ugandan colleagues learning how to best approach community challenges and utilize local resources. While experiences as a volunteer-engineer in Rakai District were diverse, the author maintained interests in applying appropriate solutions to address local water and sanitation needs.

The research for An Assessment of Water and Sanitation Infrastructure of Primary Schools in Rakai District, Uganda was carried out by the author and colleague, Ssembatya Joseph, from the Uganda Red Cross Society, Rakai Branch office. Data collection was conducted at a total of 49 primary schools; both private and government, throughout Rakai District for two weeks in September and October of 2011. The author's interest was to understand the availability and use of water among primary schools in Rakai District, as well as learn about latrine use and school's access to improved sanitation. Along with an analysis of school's existing water and sanitation infrastructure, teachers were interviewed to help identify successes, challenges, and potential improvements regarding school's existing water and sanitation conditions. 


\subsection{Uganda and Rakai District}

Uganda is a landlocked country located in East Africa covering an area of 241,550 sq. $\mathrm{km}$. It is close to the size of Oregon in the United States with a growing population of 35.9 million people1. Uganda has the fourth highest population growth rate1 in the World (3.6\%) and the second highest birth rate (1) (47 births/1000 population). Half of Uganda's population is below the age of 15 (1). It is estimated that $87 \%$ of Uganda's population lives in rural areas (2). The country retains close cultural and ethnic ties with its neighboring countries of South Sudan, Kenya, Tanzania, Rwanda, and the Democratic Republic of Congo. The landscape is both mountainous and tropical, crossed by the equator, and blessed with lakes, rivers, forests, wetlands, prairies, snowcapped mountains, and volcanoes. Uganda borders the World's second largest lake by surface area in Lake Victoria, and has the origins of the longest river in the World, the Nile. With Uganda's abundant wildlife, resources, and geography, it is said to have every piece of Africa in its country.

Today, Uganda is administratively divided into100 governmental districts in four distinct regions: central, northern, eastern, and western. From 2009-2011, the author of this report lived and worked in Uganda's central region of Rakai District. Rakai is one of Uganda's most southern district, bordering Tanzania to the south and Lake Victoria to the east, lying between longitudes $31^{\circ} \mathrm{E}, 32^{\circ} \mathrm{E}$ and latitude $0^{\circ} \mathrm{S}$. It is surrounded by Lyantonde District in the north-west, Masaka District in the north, Kalangala District in the east, and Kiruhura and Isingiro Districts in the west.

Rakai District was created under the regime of Idi Amin in 1974 (3) and remains to be an important thoroughfare between Tanzania and the rest of the county. The District is comprised of three counties including Kakuuto, Kooki, and Kyotera. These counties are made up of 18 sub-counties and three town councils. The district headquarters are located in Rakai Town Council which is reachable by tarmac road some $190 \mathrm{~km}$ away from the capitol, Kampala. Rakai Town Council is located $20 \mathrm{~km}$ west of the major highway and receives less traffic then the District's major trading centers of Kyotera Town Council and Kalisizo Town Council. Like most of the country, the majority of Rakai 
District's population lives in rural areas with only $3 \%$ living in towns (4). Rakai residents maintain a close connection to the land and pastoral way of living through animal husbandry and farming. Common crops here include banana (amatooke), potato, cassava, beans, corn (maize), ground nuts, and coffee. Rakai citizens maintain a mostly rural lifestyle and realize the importance of water, land, and agriculture.

Unfortunately, however, Rakai and Uganda still have many development, infrastructure, and health challenges, including HIVIAIDS. While Uganda has long been known for its successful fight against the disease, its impacts are still great in Rakai, where the disease first originated in the early 1980's. With an estimated 70,000 children orphaned in Rakai District because of HIVIAIDS (4), the author rarely met a person or child who hadn't been directly impacted by the disease.

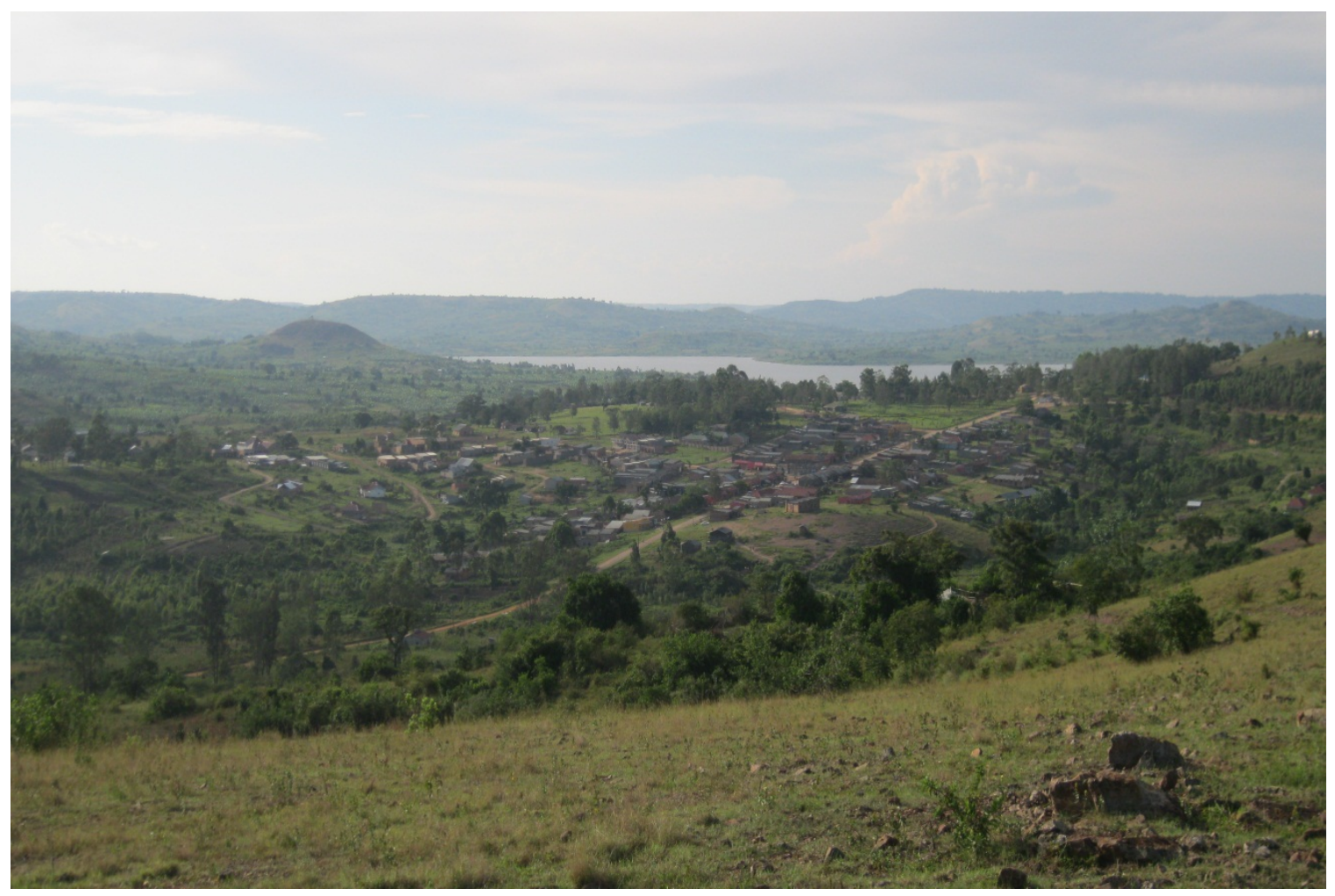

Figure 1.1: Photo of Rakai Town Council, Rakai District, Uganda. (Photo by author). 


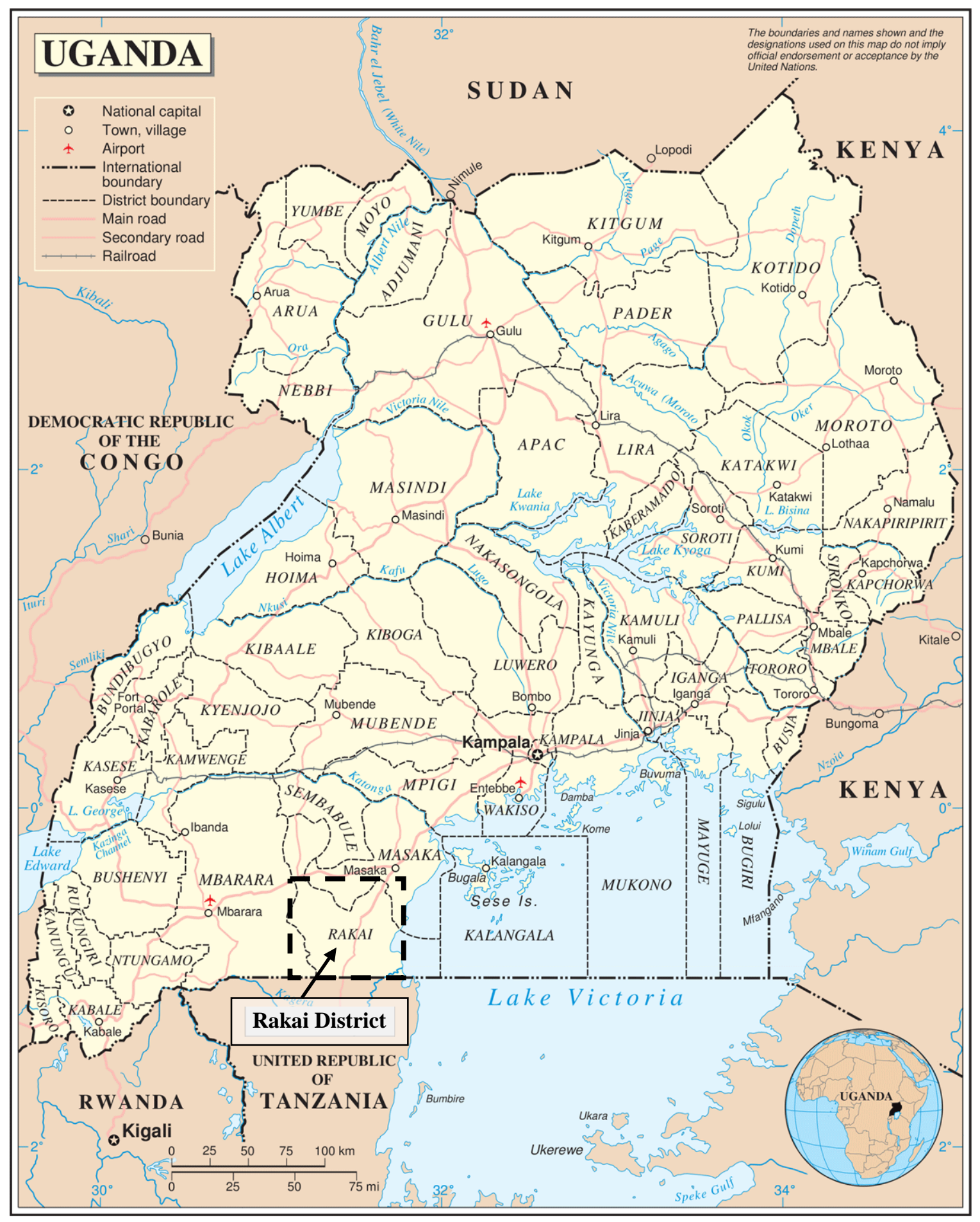

Figure 1.2: Map of Uganda with location of study in Rakai District outlined. Map reproduced from www.mapsof.net (6). 


\subsection{Water and Sanitation Statistics}

Uganda has limited access to improved water and sanitation sources which remains to be a major development and public health challenge in the country. According to the United Nations Children's Education Fund's (UNICEF) and World Health Organization's (WHO) Joint Monitoring Program (JMP), the World has actually met the Millennium Development Goal (MDG) target for sustainable access to safe drinking water (2). This goal aims to halve the number of people without access to improved water sources and sanitation by 2015 . The MDG target for improved sanitation is behind the MDG schedule and may not be met.

In Uganda, neither the water nor sanitation target for this goal has been met. With only $72 \%$ of Uganda's population with access to improved water sources, and only $34 \%$ with access to improved sanitation (5), there is still much work to be done. Comparing Rakai District regional statistics to World and National sources, we see there is also a large unmet need in providing improved sources in Rakai. According to locally initiated United Nations Development Programme (UNDP) and Uganda Bureau of Statistics (UBOS) report (4), $24 \%$ of people have sustainable access to improved water sources and $57 \%$ have access to improved sanitation. While Rakai District surpasses Uganda's total access to improved sanitation sources, sanitation is still seen as a major concern in providing safe drinking water and improving the health and safety of youth populations.

Improved water sources include piped household connections, public stand pipes, boreholes, protected dug wells, springs, and rainwater collection tanks. Improved sanitation includes ventilated pit latrines, composting latrines, pour-flush, and flush toilets. A comparison of statistics can be seen in Figure 1.3. It should be noted Rakai District results are from a different source, though definitions of improved sources remain the same. 


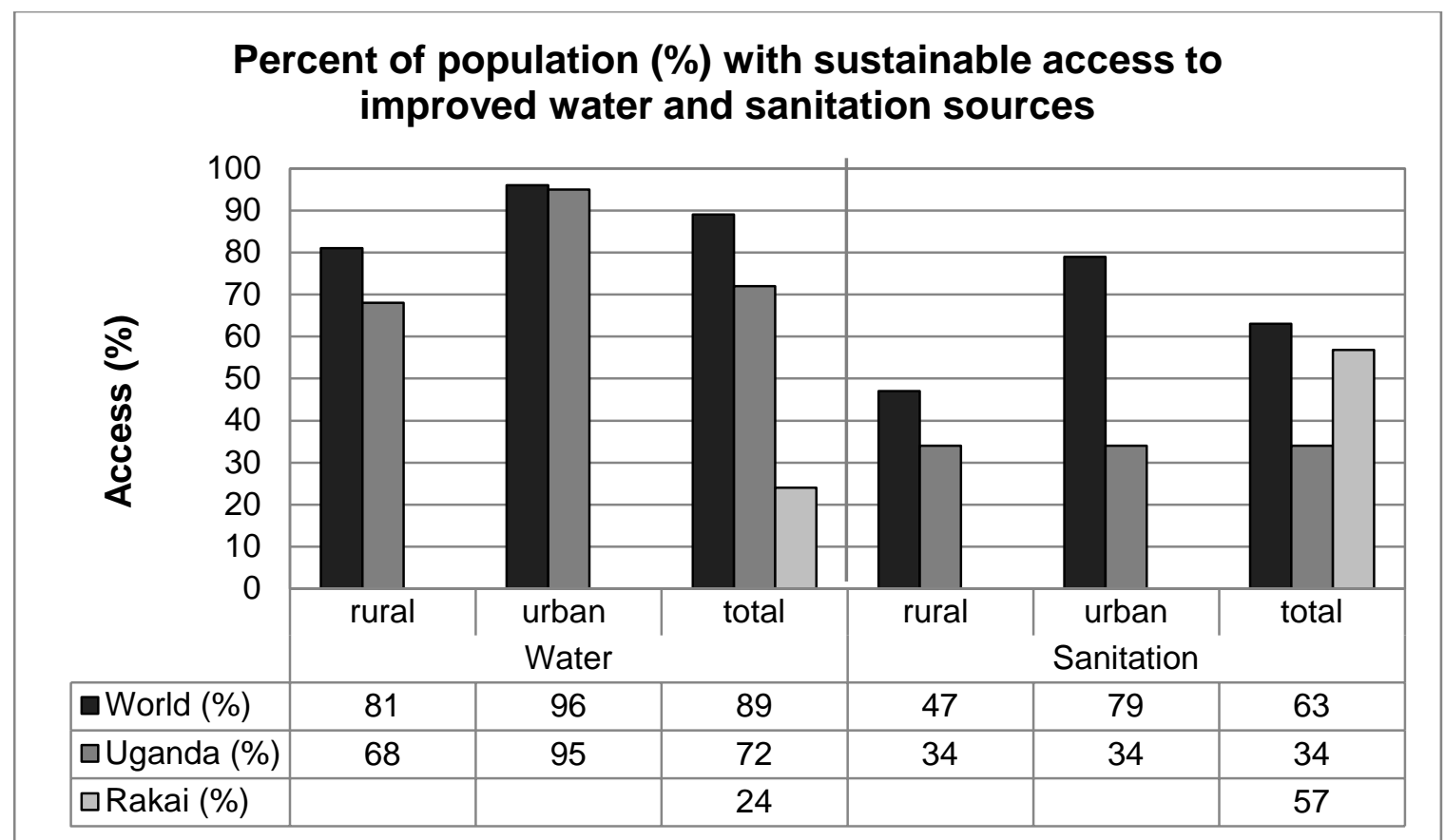

Figure 1.3: Percent of population with sustainable access to improved water sources and sanitation. World and Uganda statistics (5) compared to regional Rakai District data (4).

\subsection{Primary School Observation and Policy}

Primary education in Uganda is provided by both government and private schools. Access to primary education in government schools greatly improved in 1998 under Uganda's Universal Primary Education (UPE) system. UPE is USAID aided program which provides "free" education by the government for youth ages from 6-12. It is unclear exactly how much the Uganda government receives today in funding for the UPE system, though reports from the Ministry of Education and Sports website (7) still receives funding grants from international agencies including USAID, the European Union, and Irish Aid. According to the Ministry of Education and Sports, enrollment in UPE government schools increased from 3 million in 1997 to over 7 million in 2002. While many have benefitted from the UPE system, government schools are known to be crowded and have difficulty in providing improved water sources and sanitation. Access to improved water sources and sanitation in UPE schools continues to be dependent on a school's funding and location. 
Private schools in Uganda are also funded by international aid organizations, faith-based organizations, and private donors. Because private schools charge students tuition and boarding school fees, they also attract wealthier families and resources. Private schools may include a boarding section for pupils and are able to provide scholarships for students that perform well academically. Private schools financially support and sponsor many orphaned children in Uganda and are far-reaching in their efforts. It is common for pupils to search for friends, financial supporters, and family members which are able to help pay their education fee. Like pupils and the UPE schools, private schools will be unable to pay for all school expenses without reliable financial support

In the more rural areas of Rakai District, locally funded private schools opened when enough individuals realized a lack of educational opportunity in their community. These schools did not charge high tuition rates and often reduced fees charged to poorer families. Teachers usually knew the community and had a direct interest in the school's success. While the issue of community education was locally confronted, it was a difficult job which a few took on. Some community private schools hoped to meet government school standards and enroll in the UPE system to obtain steady financial support. If a school's private funding was substantial, then there was usually not a lot of interest to integrate into the government school system.

For research and teacher interview purposes, the author was interested in identifying school's academic calendar. As is in most of Uganda primary schools, there were three school terms in a year, with the first beginning in early February and ending in April. Term 2 began in May and was completed by mid-August. Term 3 began in midSeptember and finished by the first week of December. Many students in Rakai often missed the first week of a school term collecting money for school fees, requirements, and books. The author and colleague visited schools at the beginning of the third term. 


\section{Research Methods}

\subsection{Goals and Objectives}

There are many contributing factors which affect a school's ability to provide adequate water and sanitation services. The research objectives of this project focused on assessing the existing water and sanitation conditions of Rakai District primary schools. Methodologies appropriate to objectives and the region were designed to fill critical gaps in knowledge regarding water and sanitation infrastructure. An assessment was made to highlight each school's water and sanitation infrastructure and the successes, challenges, and potential improvements school teachers identified. The data for this assessment was analyzed by school type, including government and private.

\section{Goal 1: Assess school demographics and local resources of Rakai District primary} schools in order to identify factors which affect water and sanitation conditions

- Objective 1.1: Collect data regarding schools' location, population of pupils and teachers, and whether the school was government or privately funded

Goal 2: Assess water availability and use among Rakai District primary schools

- Objective 2.1: Collect data regarding schools' water sources, distance to sources, and estimated water use per school and pupil

- Objective 2.2: Identify the successes, challenges, and potential improvements to be made in regards to a school's water availability and use

\section{Goal 3: Assess sanitation and latrine use among Rakai District primary schools}

- Objective 3.1: Collect data regarding schools' latrine source, maintenance, and use among teachers and pupils

- Objective 3.2: Identify the successes, challenges, and potential improvements to be made in regards to a school's latrine use and hygiene practices 
A flow diagram for the study was created to identify research interests and school interview topics (Figure 2.1). The intent of the diagram is to help readers understand our research process and the water and sanitation assessment targets. The diagram indicates independent and dependent variables and allows authors to easily summarize the collected data. In doing so, researchers hope to recognize how school type (and/or location) in Rakai District may impact school's ability to provide access to improved water sources and sanitation.

How does the location and type of school affect water and sanitation infrastructure?

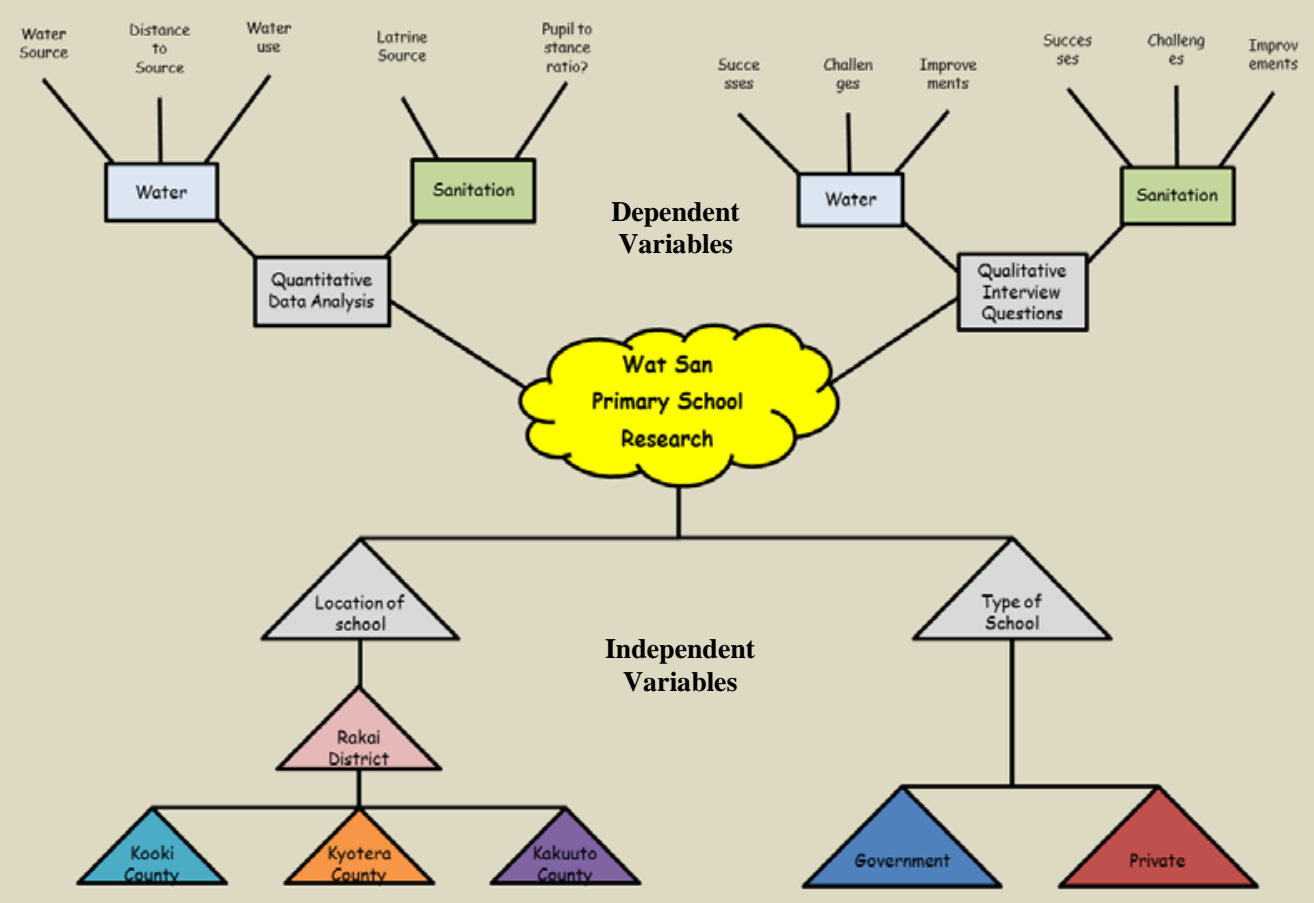

Figure 2.1: Research flow diagram for the assessment of primary schools' water and sanitation condition. 


\subsection{School Interviews}

School interviews were carried out by Red Cross volunteer Ssembatya Joseph and the author. Interview questionnaires were semi-structured with and completed in 10 days from late September to early October of 2011. Interviews were conducted at both government and private schools in Kakuuto, Kooki, and Kyotera Counties of Rakai District. Interviews were conducted in English though interpreted in Luganda, a commonly spoken language in Uganda and Rakai District, if interview questions or responses were not clearly understood.

Considerable effort was required prior to executing school visits and field interviews. Having local Rakai District partners and government officials interested and aware of the study was essential before starting. After successfully meeting with members at the Red Cross and Rakai District Water, Health, and Education government offices, the author and Red Cross colleague tentatively scheduled visits to each county and sub-county in the District. Although neither the Red Cross nor the Rakai District government offices were able to help fund the study, they were eagerly interested in results to help identify water and sanitation coverage gaps at the primary school level.

On an average day, the author and his colleague visited 4-5 schools in the District traveling approximately $50 \mathrm{~km}$ roundtrip. The schedule for data collection and school research methods permitted flexibility in the schools visited. An attempt was made to visit an equal number of government and private schools, dividing them evenly among Kakuuto, Kooki, and Kyotera counties. Schools visited each day were either near each other or along the same road maximizing fuel efficiency and minimizing project costs.

Upon arriving at a school, the author and colleague met with a director or teacher knowledgeable about the schools' history and existing infrastructure. The selection of interviewees was determined by the school itself, and required someone knowledgeable about current water sources and sanitation. Introducing ourselves on behalf of the Uganda Red Cross Society, Rakai Branch, we provided teachers with our study request and research consent form (IRB Exempt Approval M0812E) to conduct the interviews. 
Both of these forms, including a sample of our interview guide, can be found in the report Appendices.

Before interviews were conducted, teachers were given time to ask questions and request other teachers at the school to help provide in-depth interview responses. The interview itself took about 30 minutes and was recorded through authors' note taking and photographs of the school's water and sanitation sources. Interview questions were asked in the same order throughout the study and teachers were welcome to direct the conversation how they wished. Open discussions allowed researchers to follow leads and obtain more detail for each question. Interview methods were defined as being open-ended and semi-structured (8).

During the interview itself, teachers were specifically asked to provide information about the school's regional location, number of teachers and students, and whether the school was considered government or private. Data on water availability and source type, distance to sources, source reliability, and estimated water use per day was gathered to establish an understanding of the school's water resource infrastructure. The study also assessed sanitation conditions at each school in regards to latrine use and the promotion of hygiene practices like hand-washing. For each school, a pupil to latrine stance ratio was determined as well as an estimated daily water use per pupil. All quantitative values used in the study were determined through teacher interviews.

Following the more quantitative portion of the questionnaire, respondents were asked about their schools' water and sanitation successes, challenges, and potential improvement projects. Successes were defined as any positive project or technology being used by the school to help its' efforts in collecting or distributing water or providing improved sanitation facilities. A challenge was seen as any failure the school identified, or lack of resource which prohibited the school from supplying improved water and sanitation services. An improvement was defined as any potential project, or ability the school had to enhance its water and sanitation infrastructure and condition. Following the completion of the interview, visits were made to view each school's water sources and latrines to create a photo record of existing infrastructure. 


\subsection{Processing the Data}

Original copies of study materials and interview responses were transported to the United States with scanned copies remaining in Uganda. Interview responses and notes were typed up and organized by a corresponding questionnaire number. Questionnaire numbers were sequential and identified by the date a school was visited. Code numbers were provided for each school's questionnaire and grouped according to school type. The first government school visited in the study was identified as G1, the second G2, and so on. The first private school visited was identified as P1, following the same coding pattern. To preserve confidentiality of school participants, no school names or contacts have been presented in this report.

A quantitative analysis of schools' water and sanitation infrastructure was completed using Microsoft Excel ${ }^{\circledR}$. This analysis yielded knowledge of schools' common water sources, water availability and estimated use, latrine sources, sanitation condition, and hygiene practices. Interview responses were analyzed using qualitative memoing and coding methods (9). While maintaining the depth of each respondent's answers was important, coded interview responses were categorized for quantitative purposes in Microsoft Word $^{\circledR}$. Question response analysis was completed for identified successes, challenges, and improvements among government and private schools.

\subsection{Using HyperRESEARCH ${ }^{\circledR}$}

Interview responses were used for analytical purposes according to location and school type. Using the qualitative analysis software, HyperRESEARCH® (10) common interview responses regarding schools' identified successes, challenges, and improvements were recognized and delineated with specific "codes" (i.e. keywords) to quantify interview responses.

After all interview responses were coded, qualitative data was organized by a list of identifiers including school type and location. Grouping of school responses quickly 
became quantifiable and comparable through the programs filtered reports. Program reports were created to summarize interview responses and interpret relationships among the data. Data was analyzed by school type to distinguish between the specific limitations government and private schools faced. With a complete set of response codes, schools could now be categorized according to a particular question response they gave. For example, if we were interested in identifying how many schools mentioned rainwater as a "water success", we could now quantify the number schools which responded with this answer. Once all cases were entered into the program, statistical reports were converted back in to text format and inputted into Microsoft Excel $^{\circledR}$, which provided quick analysis of coded responses.

\subsection{FEWS NET Rainfall Estimates}

Through the author's personal observation, rainwater collection strategies were commonly used among many Rakai District households and schools. Rainwater collection and use has been identified as an improved water source by the MDG authors and was often discussed between this author and local Rakai District engineers.

To evaluate the potential for rainwater collection and use among Rakai District primary schools, estimated mean rainfall quantities were collected from the United States Geological Survey (USGS) Famine Early Warning Sign Network (FEWS NET). According to the program authors, this data portal "provides access to geo-spatial data, satellite image products, and derived data products in support of FEWS NET monitoring needs throughout the World" (11). This online and freely available program provided researchers with mean rainfall estimates for Rakai District at a decadal (10-day) time step from 2000 to 2012. The authors were particularly interested in collecting rainfall estimates from the FEWS NET data portal to compare against schools' existing storage volume, collection rate, and water demand. Rainfall estimation and calculation of needed storage was performed after other quantitative and qualitative analyses. 


\section{Results and Observation}

\subsection{School Study Distribution}

In this report, we compare primary schools' water and sanitation infrastructure and condition by school type. While other variables were considered for comparison, such as the location of the school in the District, only school type has been reported in our analysis. As mentioned, primary schools visited were chosen to best utilize time and money during data collection, and were usually conducted in the same county and sub county of Rakai District on a daily basis. Each school was visited once and was split among government and private school types. Travel to schools was dependent on an efficient route and good weather.

Representatives from forty-nine primary schools out of an estimated total of 345 (14\%) primary schools in Rakai District were interviewed. Interviews were conducted at 14 (19\%) primary schools in Kakuuto County, 19 (14\%) in Kooki County, and 16 (11\%) in Kyotera County. Among these, there were 29 government schools, 18 private schools, and 2 schools which identified themselves as being both private and government. At the time of the study, the overall distribution of all government and private schools in Rakai District was unknown; however, it is reasonable to state that most pupils attend government schools. For comparison reasons, we have included the "both" school group with the private schools, since they also received funding from a private source, leaving us with a total of 29 government schools and 20 private schools interviewed. In Table 3.1, school visits have been organized by school type and the county and subcounty they were located in. A map of Rakai District counties and sub-counties has been provided in Figure 3.1.

During school interviews, the author and colleague collected information on each school's pupil populations and pupil to teacher ratio. A school's pupil population impacted use of local resources and water and sanitation infrastructure made available. While pupils, teachers, parents, policy makers, and Peace Corps volunteers may easily 
recognize the lack of improved water sources and sanitation available, financial constraints of schools and policy makers often limited what a school was able to provide.

In our sample of 29 government schools and 20 private schools, the average number of pupils attending private schools was less than that of government schools. The average pupil population of private schools was 337 compared to an average of 575 pupils in government schools. The average pupil to teacher ratio at private schools was almost half that of government schools at $26: 1$ compared to $45: 1$. The average ratio of boys to girls at all primary schools sampled was 9:10. The number of pupils recorded at a school was used to evaluate the estimated water use per pupil and the pupil to latrine stance ratio.

Table 3.1: Identifying schools sampled by school type and location in Rakai District.

\begin{tabular}{|c|c|c|c|c|c|c|c|c|}
\hline \multicolumn{3}{|c|}{ Kooki County } & \multicolumn{3}{|c|}{ Kyotera County } & \multicolumn{3}{|c|}{ Kakuuto County } \\
\hline Sub-county & Priv & Govt & Sub-county & Priv & Govt & Sub-county & Priv & Govt \\
\hline Kiziba & & 2 & Kasaali & & 3 & Kakuuto & 1 & 5 \\
\hline Kyalulangira & 2 & 1 & Kyotera TC & 2 & 1 & Kasasa & 2 & 2 \\
\hline Lwamaggwa & 2 & 2 & Kalisizo & 4 & 2 & Kyebe & 1 & \\
\hline Kagamba & & 1 & Nabigasa & 1 & 2 & Kifamba & 1 & 1 \\
\hline Dwanliro & 1 & & Kirumba & & 1 & Kibanda & & 1 \\
\hline Byakabanda & & 1 & & & & & & \\
\hline Lwanda & & 3 & & & & & & \\
\hline Rakai TC & 3 & 1 & & & & & & \\
\hline Sub-total & 8 & 11 & Sub-total & 7 & 9 & Sub-total & 5 & 9 \\
\hline Total & \multicolumn{2}{|c|}{19} & Total & \multicolumn{2}{|c|}{16} & Total & \multicolumn{2}{|c|}{14} \\
\hline \multicolumn{9}{|c|}{ Private schools sampled $=20$} \\
\hline
\end{tabular}




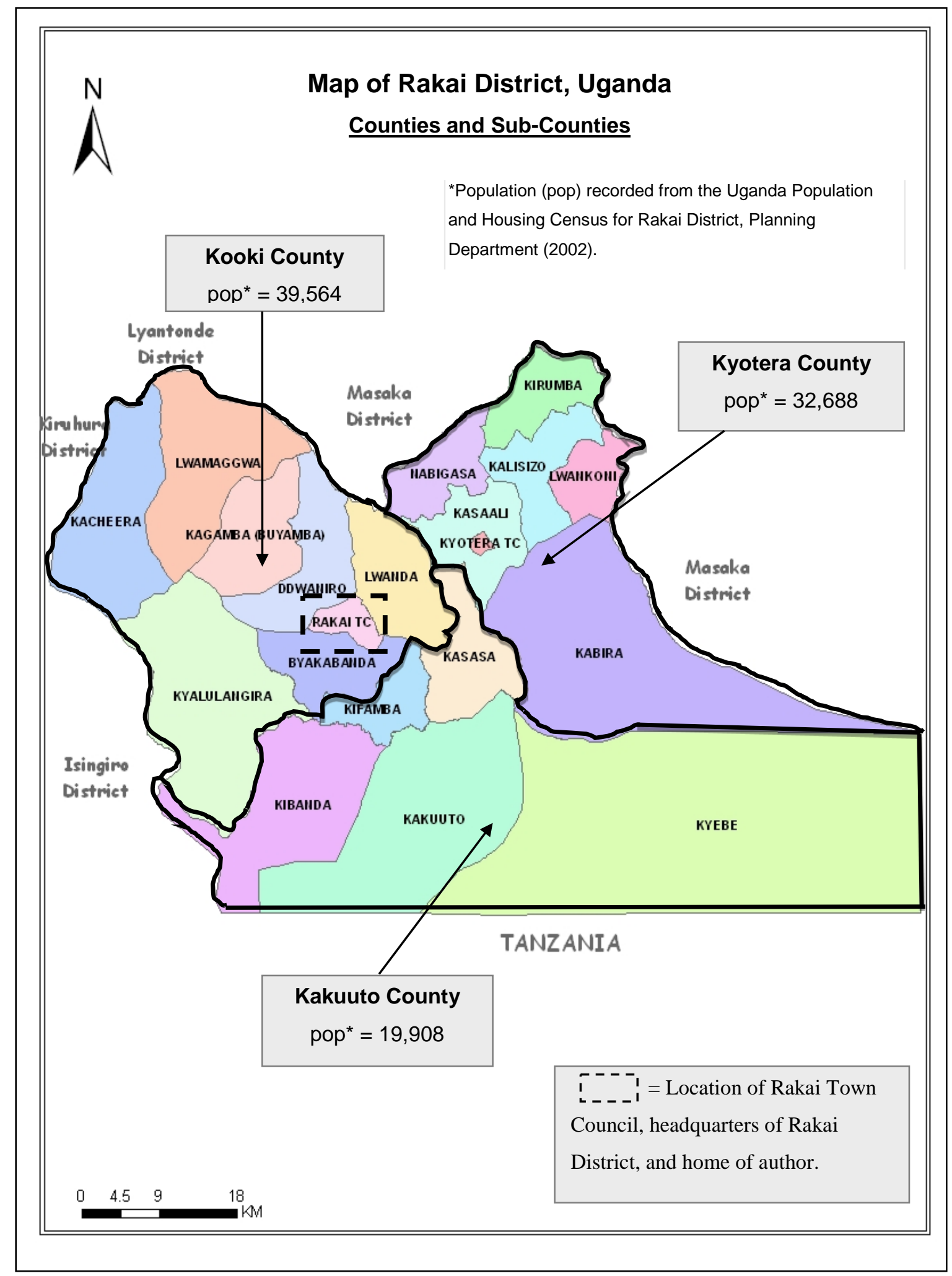

Figure 3.1: : Map from the 2010 Millennium Development Report Update (4) of Rakai District with population per county provided by the Uganda Population and Housing Census for Rakai District, Planning Department (2002). 


\subsection{Quantitative Data Summary}

A quantitative analysis was performed to evaluate existing water and sanitation conditions and the infrastructure available at Rakai District primary schools. Information was gathered on each school's specific water collection and distribution strategies and latrine use among its pupils. In our quantitative data analysis and summary, we analyze water and sanitation infrastructure and condition by school type.

\subsubsection{Water Sources, Distance, and Use}

Acquisition and maintenance of school water sources was dependent on the available funding of both government and private schools. A variety of water sources including rainwater collection tanks, shallow wells, boreholes, piped water supply systems, and open sources (Figure 3.2) were used by primary schools in Rakai District. Open sources, including natural, but unprotected springs, lakes, and rivers were common (55\%) amongst both government and private schools. While open sources were not preferred and often required long distances to travel to collect water (an average distance of $1.65 \mathrm{~km}$ ), water from these shared sources was essentially free and used.

Other water sources including shallow wells and boreholes were also common among government and private schools, with average collection distances of $1.65 \mathrm{~km}$ and 0.85 $\mathrm{km}$, respectively. Distances to school rainwater tanks and a piped water supply system were zero, since these sources were located within a school's compound. Average distances to water sources did not significantly differ between school types. Most schools also collected water from multiple sources to meet water needs. Government schools relied heavily on rainwater collection (93\%), while most private schools (60\%) had access to public and privately owned piped water supply systems. Water from piped water systems came from local sources including lakes, rivers, or springs.

While a variety of rainwater tank materials (metal, ferro-cement, and plastic) and technologies exist in Rakai District, tanks were not always in working condition. The 
percentage of working tanks in private schools was 94\%, while the percentage of working tanks in government schools was only $64 \%$. Non-functioning rainwater tanks are due to a number of social and economic factors, including a lack of funding for maintenance and repair, and a sense of ownership among teachers and school directors. A community's use of schools' rainwater tanks use was often prohibited by the school due to reckless use and damage to existing tank parts (outer shell, spigot, gutters). The number and size of working rainwater tanks was used to measure storage capacity (L) per school and per pupil. The average storage capacity of rainwater tanks was higher among private schools at 16,000 L per school and $48 \mathrm{~L}$ per pupil, compared to $10,000 \mathrm{~L}$ per school and $17 \mathrm{~L}$ per pupil at government schools. The measurement of storage capacity per pupil was determined by dividing daily water use per school (L) by each school's pupil population (pupil). The higher storage rate per pupil at private schools is partially determined by a lower pupil population.

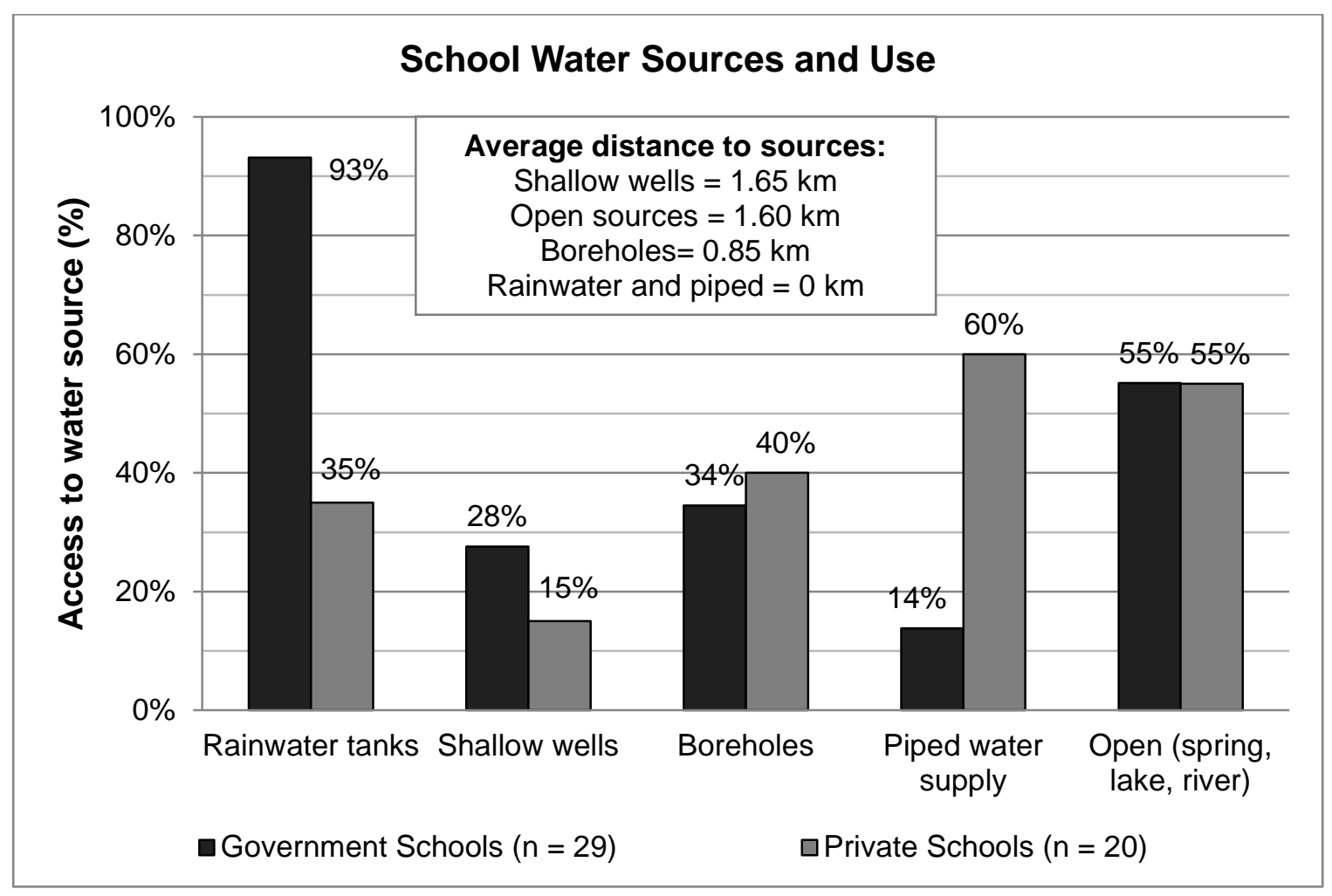

Figure 3.2: Identifying school water sources, average distance to sources, and percentage of use by school type. 
The estimated water use per school was higher among private schools at an average of 1300 L/day (Table 3.2). Government school's water use was significantly less than that of private schools at an average of $389 \mathrm{~L} /$ day. Due to large differences in estimated water use, including a maximum water use value of 10,000 L/day at one private school, and a minimum of $30 \mathrm{~L} /$ day at one government school, it is more accurate to compare water use values of private and government schools by observing median values of 550 L/day and 300 L/day, respectively. One observed reason of higher water use at private schools was the need for water for boarding section students, which required more daily water use for pupil cleaning, drinking, and meal preparation. In our sample, it is estimated that $20 \%$ of all private school students are in boarding sections.

Table 3.2: Estimated daily water use values per school by school type.

\begin{tabular}{|l|c|c|}
\hline Water use per school (L/day) & Private $(\mathbf{n = 2 0 )}$ & Government $(\mathbf{n = 2 9 )}$ \\
\hline Average water use per school & 1,296 & 389 \\
\hline Maximum water use per school & 10,000 & 1440 \\
\hline Minimum water use per school & 100 & 30 \\
\hline Median water use per school & 550 & 300 \\
\hline Standard deviation & 2196 & 328 \\
\hline
\end{tabular}

Estimated water use values per pupil were also determined for government and private schools visited (Table 3.3). Estimated water use values per pupil were equated by dividing the estimated water use values per school by each school's pupil population. The average water use per pupil value at private schools (3.4 L/day) was almost 5 times that of government schools. Once again, because of high variation among maximum and minimum water use per pupil data, it was more logical to compare estimated water use values per pupil by reporting median values. Median values of $2 \mathrm{~L} /$ day per pupil and $0.5 \mathrm{~L} /$ day per pupil were recorded in private and government schools, respectively. 
Table 3.3: Estimated daily water use values per pupil by school type. Author's use a recommended daily water use value of 2 L/day per pupil.

\begin{tabular}{|l|c|c|}
\hline Water use per pupil (L/day) & Private $(\mathbf{n = 2 0})$ & Government $(\mathbf{n = 2 9 )}$ \\
\hline Average water use per pupil & 3.4 & 0.7 \\
\hline Maximum water use per pupil & 12.2 & 3.2 \\
\hline Minimum water use per pupil & 0.4 & 0.1 \\
\hline Median water use per school & 2 & 0.5 \\
\hline Standard deviation & 3.2 & 0.7 \\
\hline
\end{tabular}

An initial assessment of water and sanitation was to determine the number of primary schools providing a minimum recommended water use and latrine use values. Through previous work in the District, the author found a recommended daily water use value of at least 2 L/day per pupil from local organizations and health workers. With both government and private school pupils spending at least 8-hours a day in school, having access to a sufficient quantity of water remains essential. While we acknowledge that larger schools and schools with boarding sections require more water for multiple water uses including bathing, cooking, and cleaning, the overall quantity of daily water use at both government and private schools is still significantly low. In our analysis of schools' water consumption, only $7 \%$ of government schools visited, and $50 \%$ of private schools visited were able to meet this daily water use recommendation (Figure 3.3). 


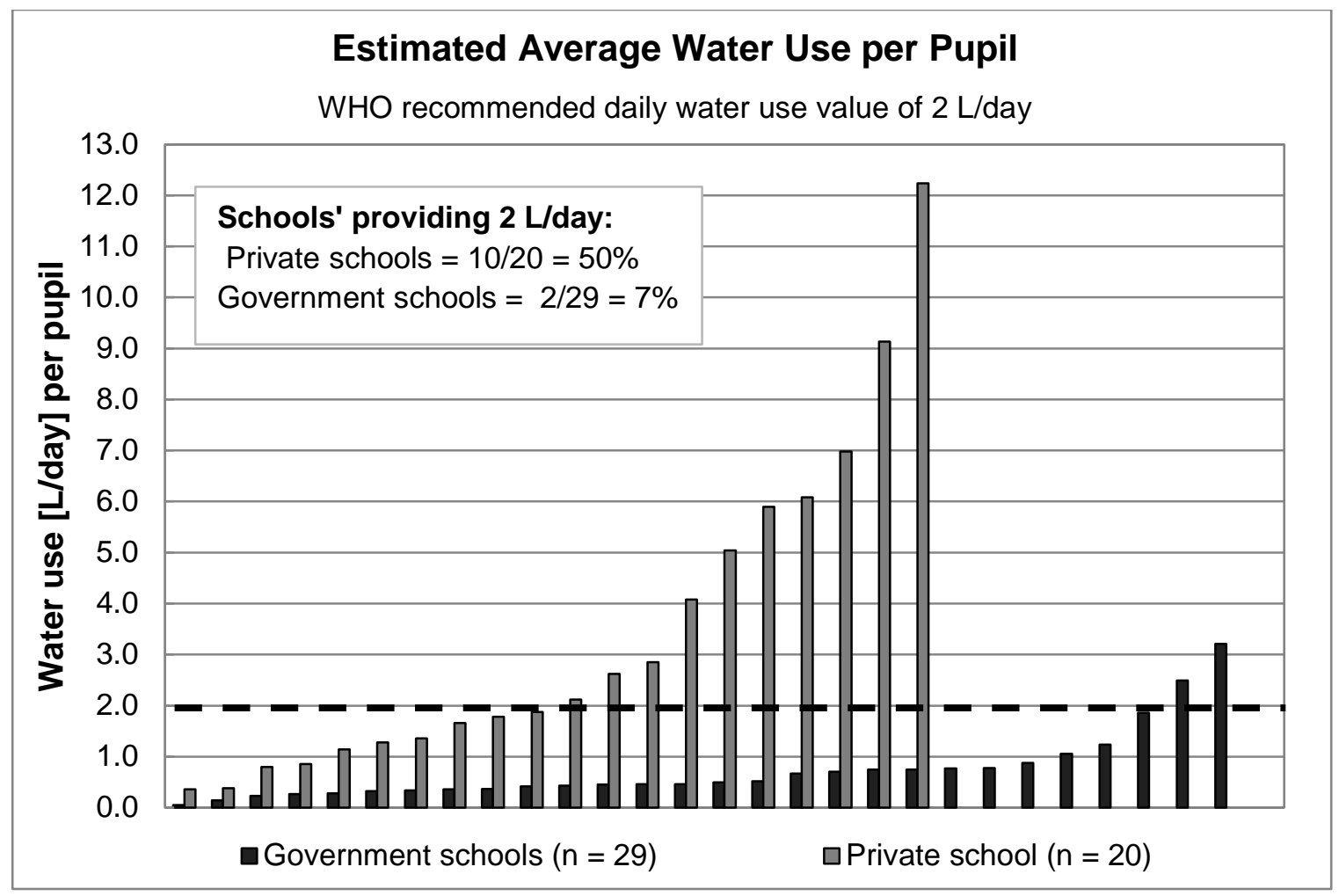

Figure 3.3: Schools' estimated average daily water use value per pupil.

\subsubsection{Sanitation and Latrine Use}

Ventilated improved pit (VIP) latrines were by far the most common latrine source for both government and private primary schools studied in Rakai District (Figure 3.4). VIP latrines were available at $90 \%$ of government schools visited and $55 \%$ of private schools. Simple pit latrines were the next most common latrine among government schools. Other latrine sources included composting latrines and pour-flush latrines, though each was rarely present. Most VIP and simple pit latrines were large single pit, hand dug, holes constructed with a superstructure of locally clay fired bricks, cement and mortar, and corrugated iron sheeting for its roofing. Plastic ventilation pipes are sold in local hardware stores and installed for single pit VIP latrine structures, but screening is rarely used to minimize the attraction of flies. 


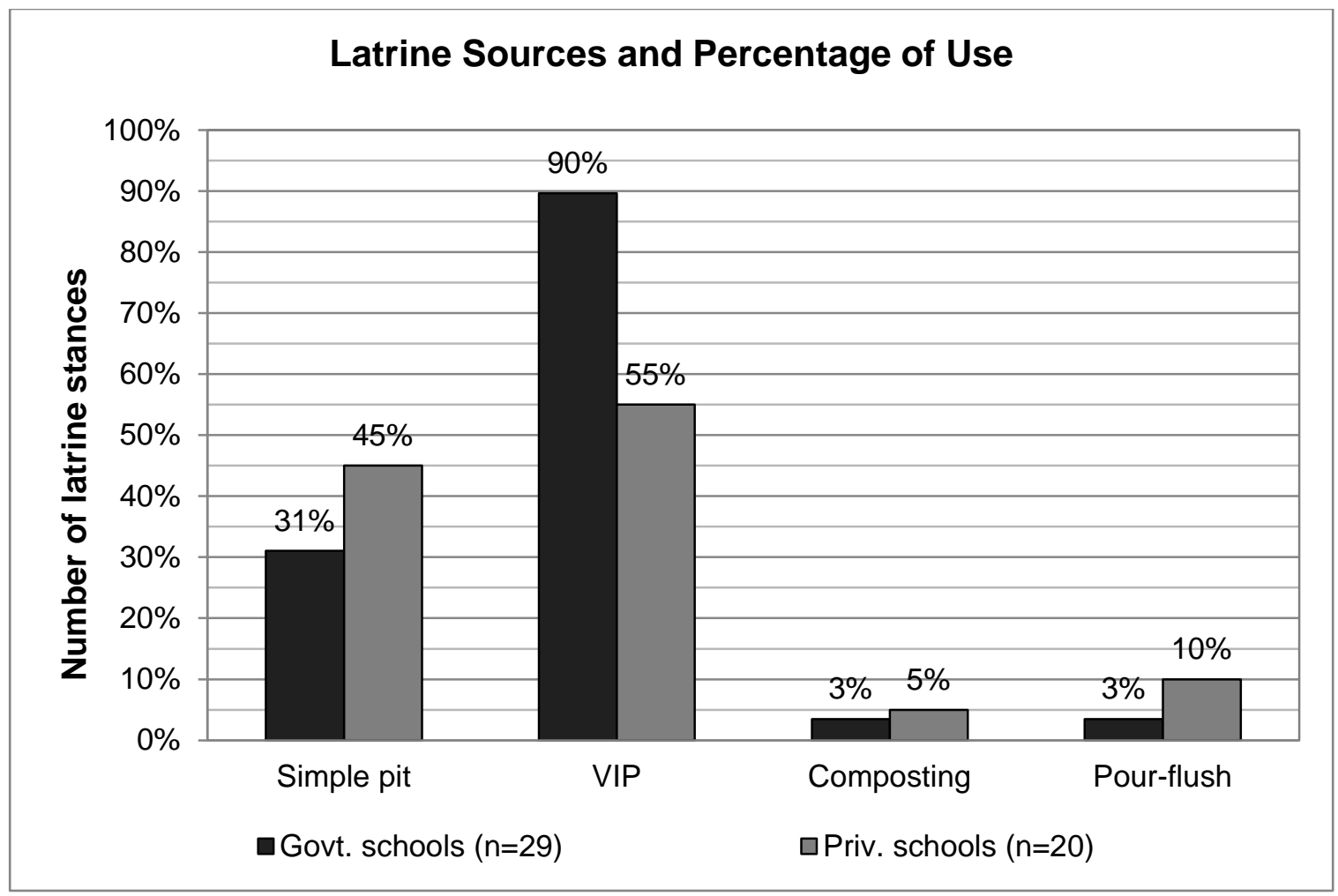

Figure 3.4: School latrine sources and percentage of use by school type.

Latrines were often located within a school compound in an average of 10 or 13 stance block structures (Table 3.4). A latrine stance is defined as one latrine pit opening, or single toilet, which is separated by a latrine door, a roof, and 3 walls. Schools often had two or more latrine blocks available, thus resulting in various school populations (i.e. older boys) to use different latrine structures. An average of 10 stances per school was identified in private schools; while an average of 13 stances per school was recorded at government schools. Due to a large difference among minimum and maximum latrine stance quantities, median values of 7 stances per school at private schools and 12 stances per school at government schools is a more appropriate comparison to make. 
Table 3.4: Latrine stance quantities by school type.

\begin{tabular}{|l|c|c|}
\hline School latrine stance data & Private $(\mathbf{n}=\mathbf{2 0})$ & Government $(\mathbf{n}=\mathbf{2 9})$ \\
\hline Average stances per school & 10 & 13 \\
\hline Maximum stances per school & 37 & 30 \\
\hline Minimum stances per school & 2 & 4 \\
\hline Median stances per school & 7 & 12 \\
\hline Standard deviation & 10 & 6 \\
\hline
\end{tabular}

The pupil to latrine stance ratio per government and private schools is an important factor in evaluating a school's overall sanitation condition (Table 3.5). With high pupil populations, minimal water availability, and an inadequate number of latrine structures, sanitation in primary schools is a great challenge. According to the 2007 Rakai District Sanitation Ordinance, the recommended pupil to latrine stance ratio for schools is 40:1. The maximum pupil to stance ratio recorded in this study was well above this ordinance at 190:1 with minimum value of 2:1. As seen in Table 3.5, the average and median pupil to latrine stance ratio values were very close to the District ordinance. Overall, government schools in Rakai had more difficulty in meeting this sanitation ordinance.

Table 3.5: Pupil to latrine stance ratios by school type.

\begin{tabular}{|l|c|c|}
\hline Pupil to latrine stance ratios & Private $(\mathbf{n = 2 0})$ & Government $(\mathbf{n = 2 9})$ \\
\hline Average pupil to stance ratio & $48: 1$ & $56: 1$ \\
\hline Maximum pupil to stance ratio & $131: 1$ & $190: 1$ \\
\hline Minimum pupil to stance ratio & $2: 1$ & $19: 1$ \\
\hline Median pupil to stance ratio & $40: 1$ & $46: 1$ \\
\hline Standard deviation & 29 & 39 \\
\hline
\end{tabular}

In our assessment, we were also interested in identifying the number of schools which met the 2007 Rakai District Sanitation Ordinance (Figure 3.5). Though we were not interested in policing schools visited, we did feel it was important for local development organizations and the District to identify sanitation and latrine use trends. In total, only 
$34 \%$ of government schools studied met the sanitation ordinance, while $50 \%$ of all private schools met the recommended 40:1 pupil to latrine stance ratio.

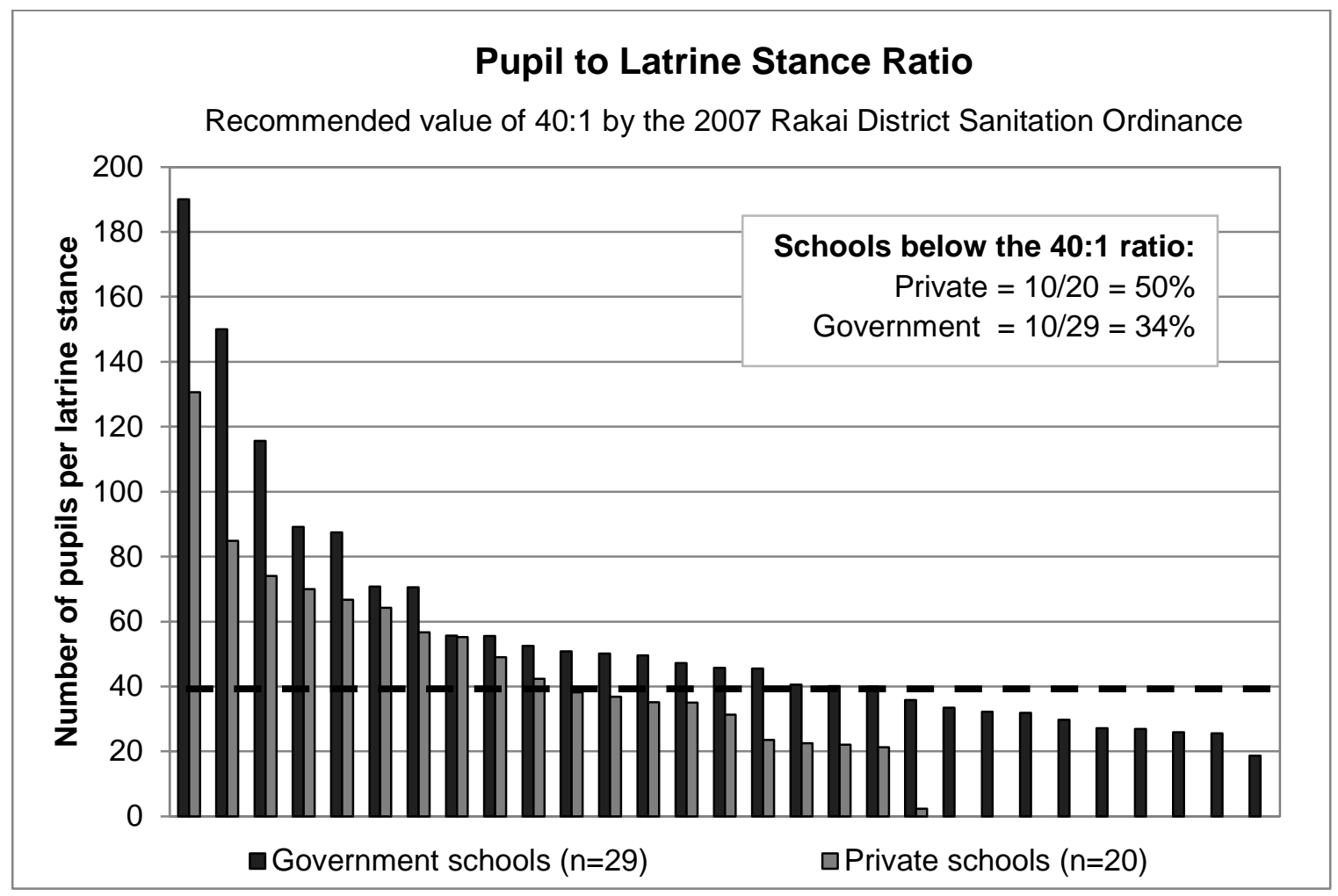

Figure 3.5: Schools' calculated pupil to latrine stance ratios.

Most school latrines are in poor condition and in need of repair. Though many schools did not have the resources or money to repair existing latrine infrastructure, they were used anyhow and cleaned by pupils and teachers alike. A common observation was that latrine stance holes were not covered with wooden pit covers, which created breeding grounds for flies. While available, latrine pit covers were not used in government schools (0\%) and rarely used in private school (15\%). It appears the relationship between latrine use, hygiene, and health was not a major concern among school users. It should also be noted that government schools also had a more difficult time in providing an adequate water supply and soap for hand washing after latrine use. Minimal water for sanitation was identified by some teachers as a limiting factor as to improving sanitation conditions. Further data on sanitation and hygiene practices per school type are found in Figure 3.6. 


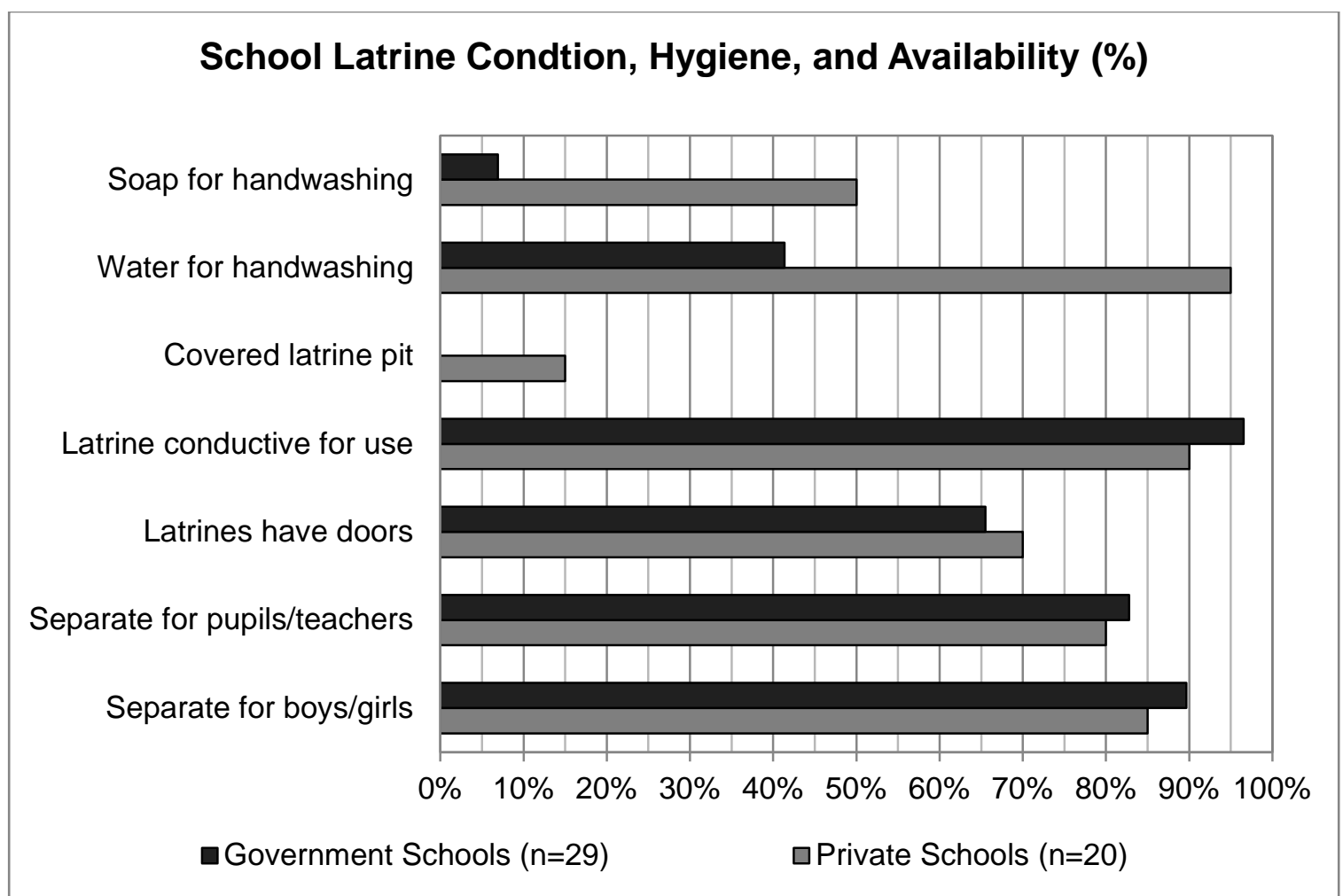

Figure 3.6: Interview responses concerning latrine use and hygiene.

\subsection{Qualitative Interview Responses}

The qualitative analysis of water and sanitation interviews was performed to identify the successes, challenges, and improvements teachers identified in Rakai District primary schools. Interview discussions focused on water collection and distribution strategies, sanitation, latrine use, and the study of water and sanitation infrastructure. In this analysis, interview responses were grouped by school type and plotted according to a response rate (\%). For example, a rainwater availability response among government schools was identified as a "water success" 16 times out of a total of 40 government responses, thus giving it a $40 \%$ response rate for the question. The number of responses varied for each question, and differed among government and private schools. In the following analysis, questions concerning schools' water and sanitation successes, challenges, and potential improvements have been answered by school teachers and presented to help establish research recommendations. 


\subsubsection{Water Successes, Challenges, and Improvements}

There were a total of 8 coded responses for "water successes" (see Figure 3.7). The most common interview response from government schools in regards to schools' water successes was their use and availability of rainwater at $40 \%$. Other common responses from government schools included a shared workload among water users at $15 \%$ and a short distance to water sources at $13 \%$. A shared work load response corresponds to a school's ability to handle water stresses and distribute collection efforts amongst teachers and pupils. Access to a piped water system was the highest success identified by private schools at $24 \%$, followed by rainwater collection at $21 \%$, and a shared work load at $17 \%$. The least common response among both school types was a "none identified" or "none answered" code, which refers to teachers stating they had no known water successes.

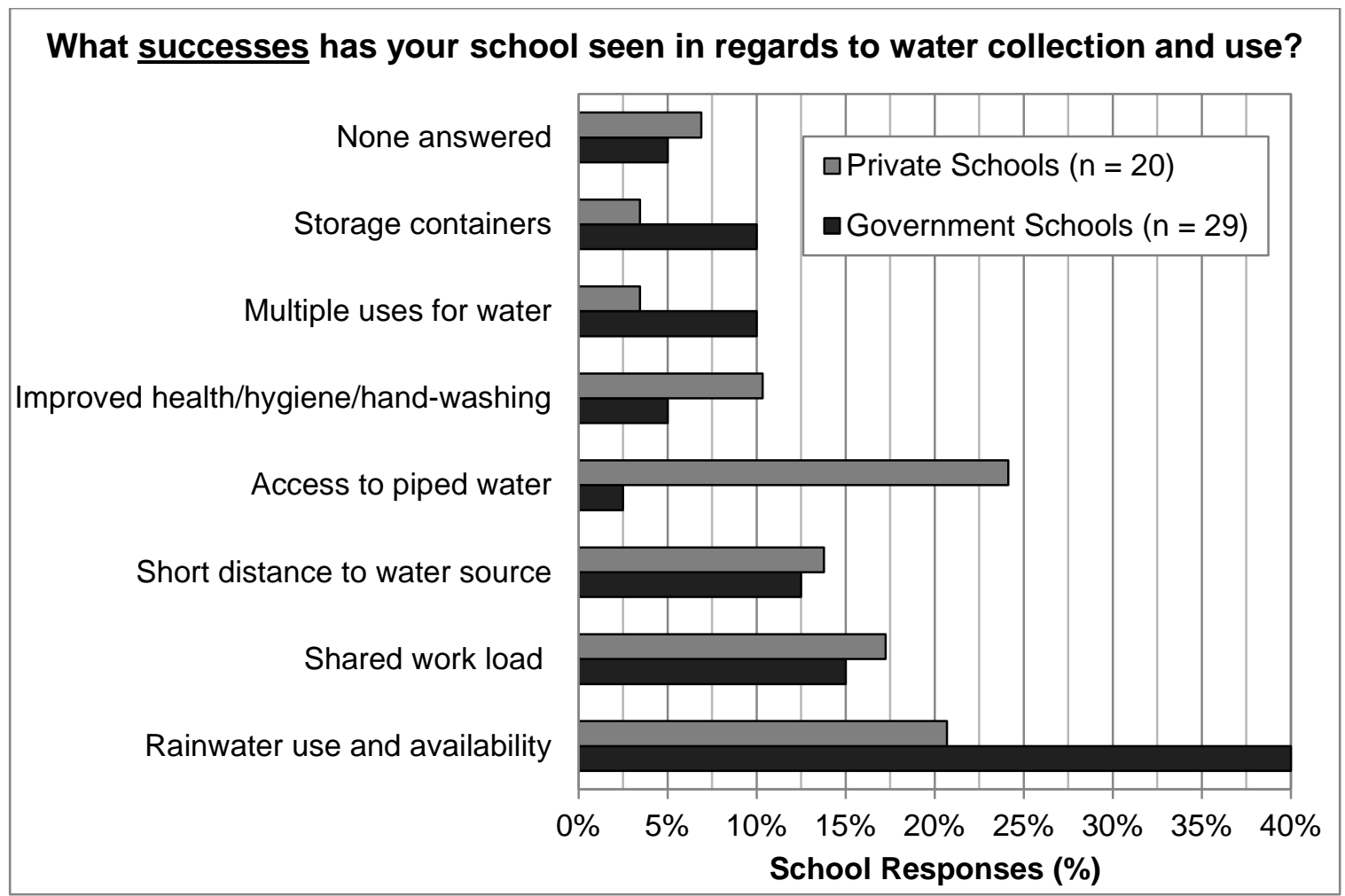

Figure 3.7: Interview responses concerning water successes by school type. 
There were a total of 10 coded responses identified for government and private schools' "water challenges" (see Figure 3.8). The biggest water challenge amongst government schools was a scarcity and/or lack of available water sources (21\%). Though rainwater collection was identified as a success at government schools, this quantity of water was often not enough, which pupils and teachers both experienced first-hand. Another challenge amongst government schools was conflict with neighboring communities at a response rate of $17 \%$. No private schools identified community conflict as a challenge to water infrastructure and distribution efforts. Community conflict included damaged rainwater tanks, stolen taps, and prohibited use of schools' water supply demanded by the school. The highest response rate amongst private schools' water challenge was shared between high cost of supply water and the lack of water storage containers at $20 \%$. While private schools had more access to piped water supply systems than government schools, they reported that access to piped water and a power supply to deliver piped water was not consistent. Distance and time to collect water, as well as poor water quality, were also referred to as water challenges by both school types.

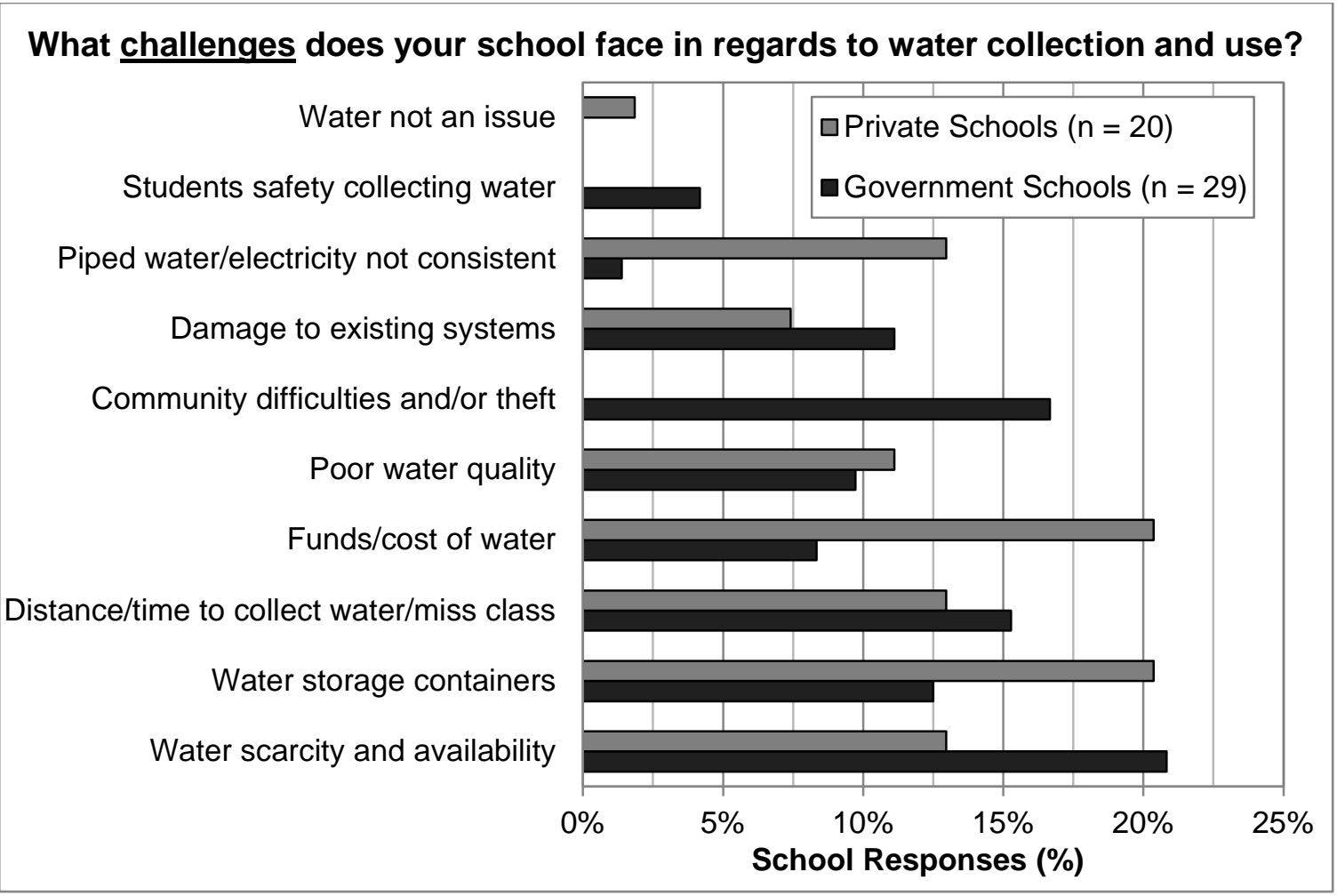

Figure 3.8: Interview responses concerning water challenges by school type. 
There were a total of 9 coded responses identified for government and private schools "water improvements" (see Figure 3.9). The most common water improvement response from government (27\%) and private schools (28\%) was to address rainwater collection needs. Water treatment (14\%) and protecting water sources from community members (16\%) were common responses among government schools. Water treatment methods included boiling water and the use of a commercially sold chemical solution called WaterGuard ${ }^{\circledR}$ were common responses among both school types. Private schools identified obtaining and/or improving a piped water supply system (17\%) as a potential water improvement. The least common response among schools was a desire to reach out to local community members and parents to improve water conditions for all.

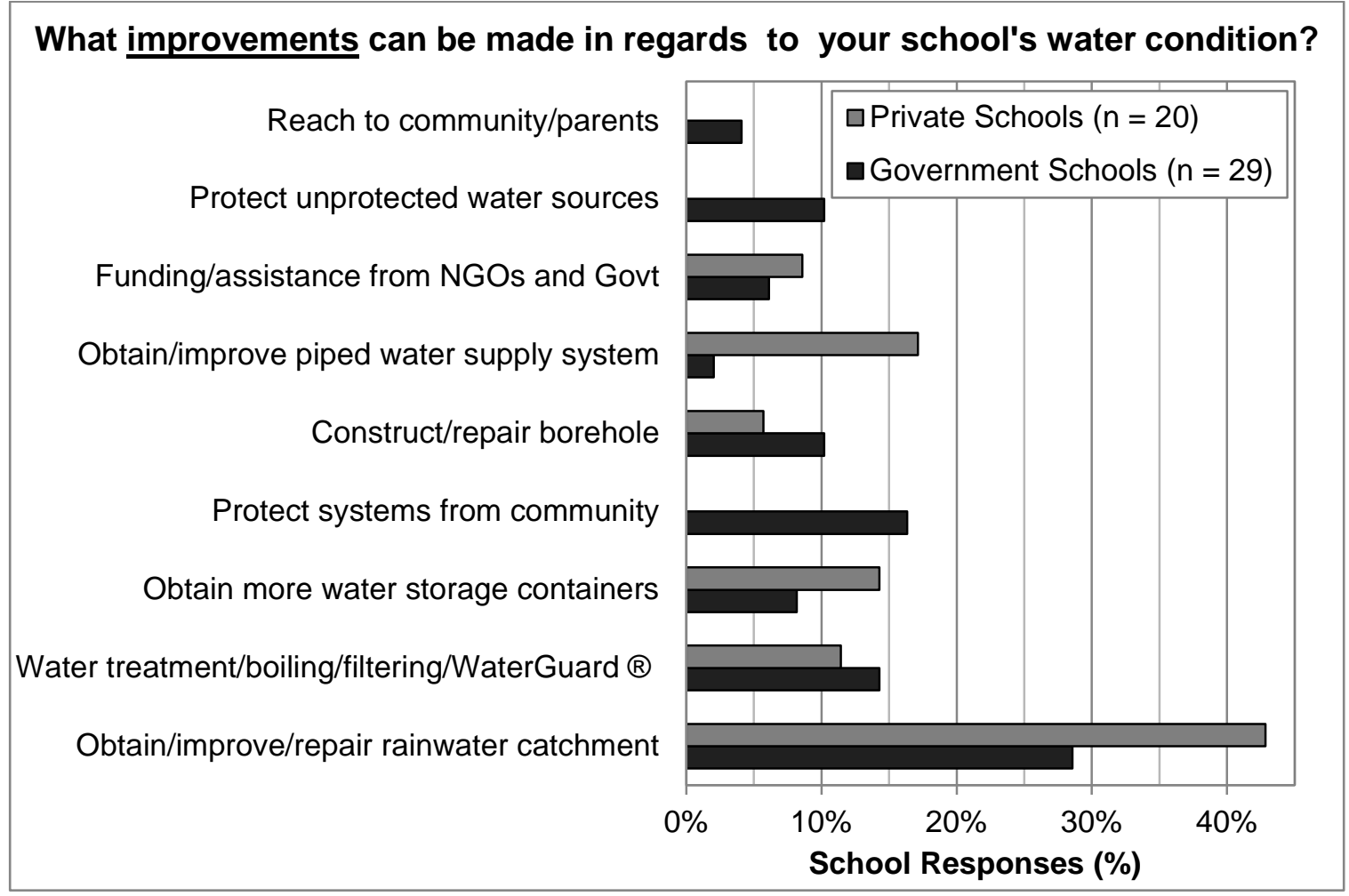

Figure 3.9: Interview responses concerning water improvements by school type. 


\subsubsection{Sanitation Successes, Challenges, and Improvements}

A total of 10 coded responses were recorded as "sanitation successes" (see Figure 3.10). Interview responses show government schools had the highest interest in increasing the number of latrine stances (28\%). Education was the second most identified response amongst government schools (22\%) and the most common response amongst private schools (24\%). Keeping latrines clean by students and/or hired workers was also recognized by both government and private schools as a sanitation success. Eleven percent of government schools indicated that they had no sanitation successes whatsoever.

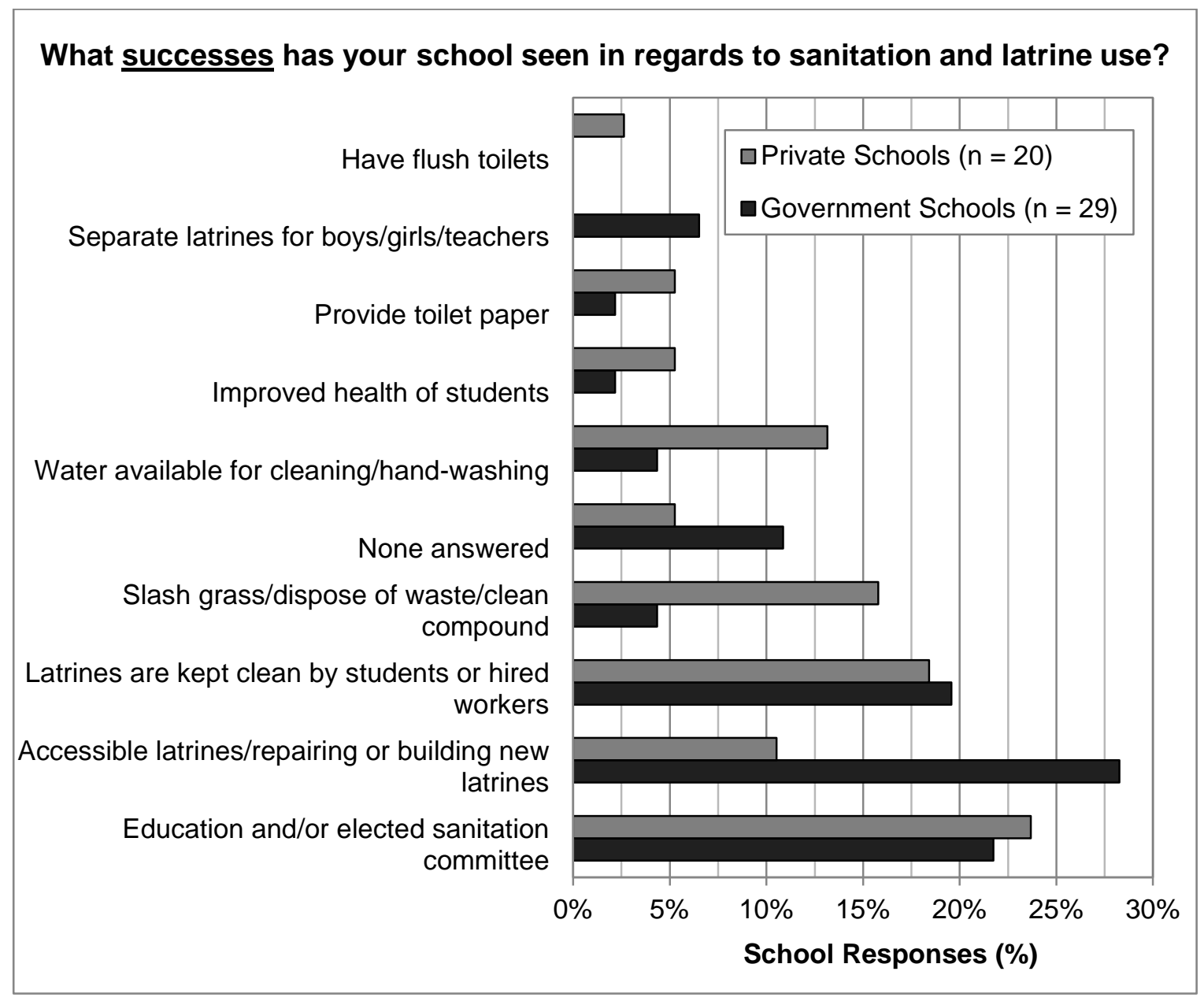

Figure 3.10: Interview responses concerning sanitation successes by school type. 
Many "sanitation challenges" were addressed by school teachers (see Figure 3.11). In total, there were 14 coded responses for government and private schools, including the value of educating pupils on health and hygiene, the distance and/or location of latrines, inadequate waste disposal methods, lack of a separate latrine for teachers, the misuse or lack of cleaning equipment, the lack of hand-washing facilities and soap, and challenges with local communities. The biggest sanitation challenge mentioned by both government (27\%) and private schools (28\%) was a minimal number of latrine stances. When school latrines became full, each school was responsible for emptying or digging a new pit for a new latrine structure. The smell of latrines was not seen as an issue by most schools. 


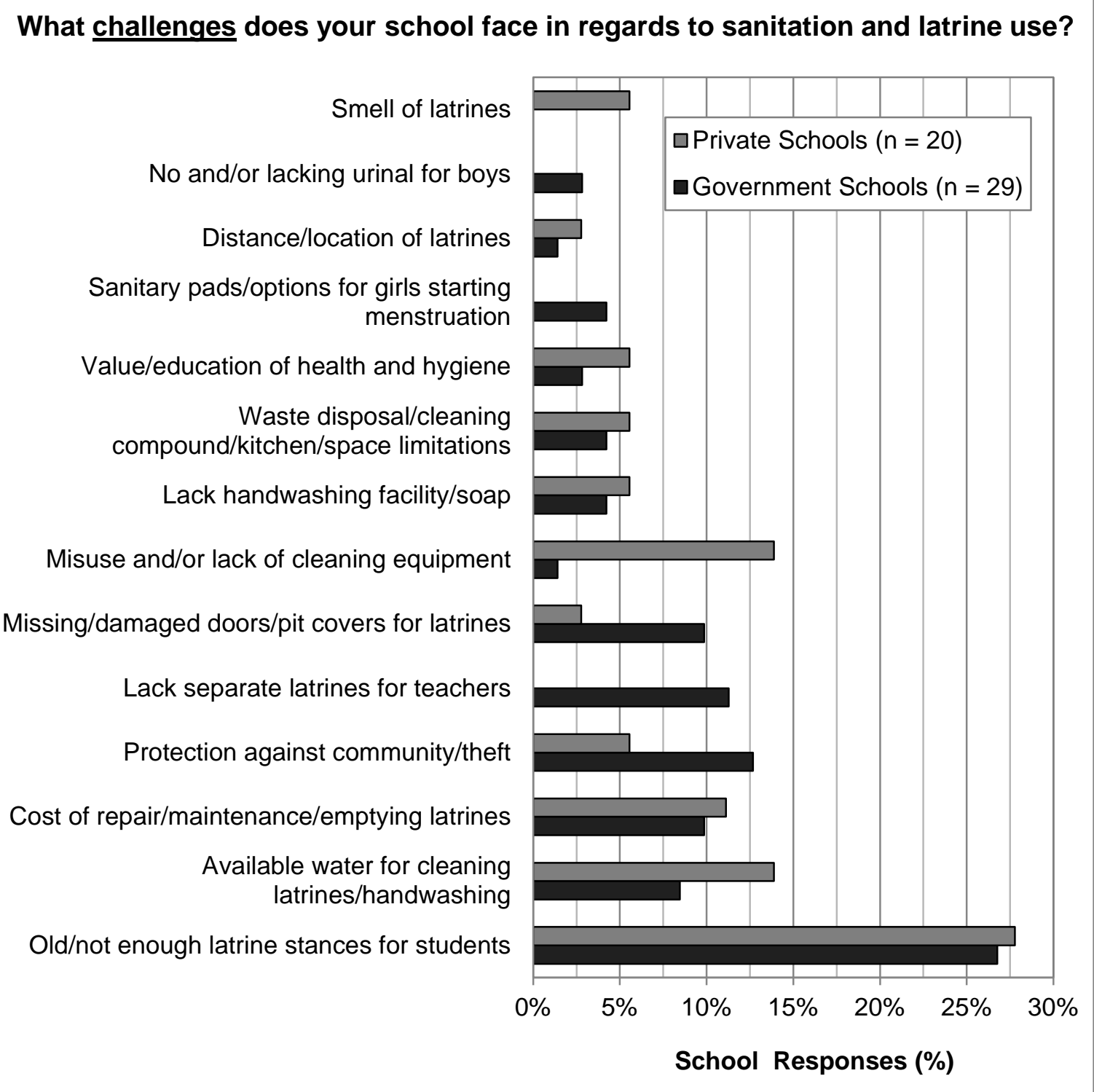

Figure 3.11: Interview responses concerning sanitation challenges by school type.

There were a total of 14 coded responses for all "sanitation improvements" (see Figure 3.12). After understanding sanitation challenges in Rakai District primary schools, the obvious response to "improving sanitation" was to construct more latrines, which is exactly what teachers identified in both government (38\%) and private (33\%) schools. Remaining responses for government schools were almost equally distributed amongst other responses. Private school responses focused more on improving water supply 
(18\%), waste disposal (15\%), and educating pupils on healthy sanitation practices (12\%). The relationship between water and sanitation was recognized by school teachers in the study and was an important issue in addressing sanitation challenges.

\section{What improvements can be made in regards to your school's sanitation} condition?

Provision of cleaning/sanitary materials Fumigate bush for mosquitos/cement floor in dormitory

Construct septic tank

Spoke about composting/ecosan latrines

Provide kitchen/doors for latrines Latrines for teachers

Protection from/cooperation with community Permanent facility for boys urinal/girls on menstruation Acquisition of funding Improve handwashing facility/provide water/soap

Promotion/education/sensitization of sanitation

Improve waste disposal/drainage/cleanliness

Improve water supply/storage/catchment

Construct new/more latrines/stances

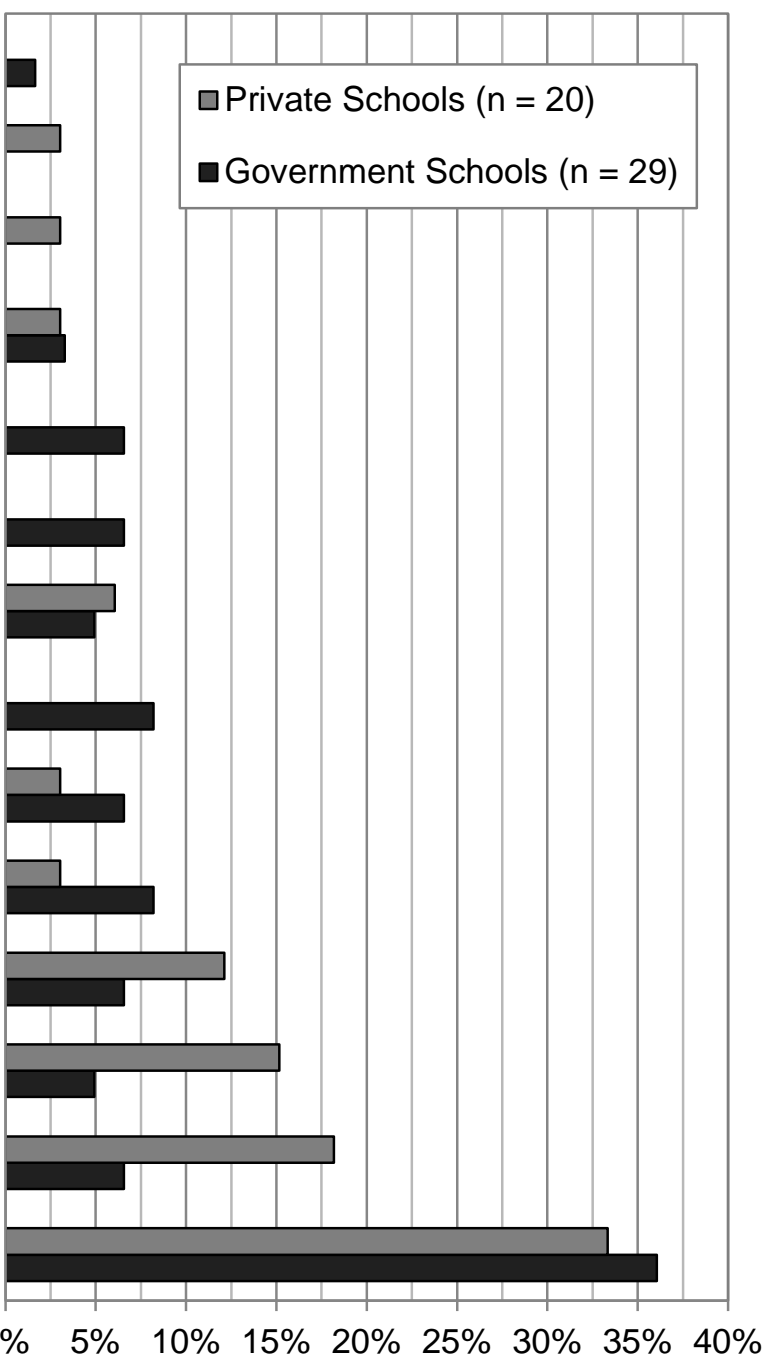

School Responses (\%)

Figure 3.12: Interview responses concerning sanitation improvements by school type. 


\subsection{Rainfall Estimates and Water Demand}

Rainfall estimates gathered from the USGS FEWS NET data portal allowed the author to evaluate potential rainfall quantities for Rakai District and Kakuuto, Kooki, and Kyotera Counties. With estimations $(\mathrm{mm})$ provided on a decadal time step for Uganda's district and county level, calculations were made using rainfall estimates to help determine the required storage volume for $100 \%$ rainfall collection rates at government and primary schools. With decadal rainfall estimates gathered from 2000 to 2012, mean rainfall values were plotted against average water demand every 10-days for both government and private schools sampled (see Figure 3.13).

From 2000 to 2012, rainfall estimates across Rakai District were fairly consistent with a cumulative average of $1136 \mathrm{~mm} / \mathrm{yr}$. School water demand $(\mathrm{mm})$ was dependent on what government and private schools estimated daily water use at $(0.7 \mathrm{~L} /$ day per pupil for government schools and 3.4 L/day per pupil for private schools) with a minimum value of 2 L/day per pupil used (for design purposes) if schools did not meet this recommendation. Water use values were then extrapolated over a 10-day period (7days in school) since they would be compared to decadal rainfall estimations.

School water demand was also dependent on the average pupil population of government (574 pupils) and private schools (337 pupils). Since rainfall collection areas (i.e. roof surface area collecting rainfall) at schools were not measured during data collection, an estimated collection area of $275 \mathrm{~m}^{2}$ per school was used for both government and private schools. This estimated collection area was derived from a Peace Corps Uganda volunteer study in 2011 in Rakai District which calculated average household collection area to be $50 \mathrm{~m}^{2}$. Schools were estimated by this author to be roughly five times larger than the average house, however, it is recommended the distinction between schools types and location be taken into consideration in future studies. The required collection areas per pupil, however large, were determined to provide daily water use values for average pupil populations at both government $(0.48$ $\mathrm{m}^{2} /$ pupil) and private $\left(0.82 \mathrm{~m}^{2} /\right.$ pupil) schools. A comparison of mean rainfall estimates 
from 2000 to 2012 for Rakai District and school's calculated water demand is shown in

Figure 3.13.

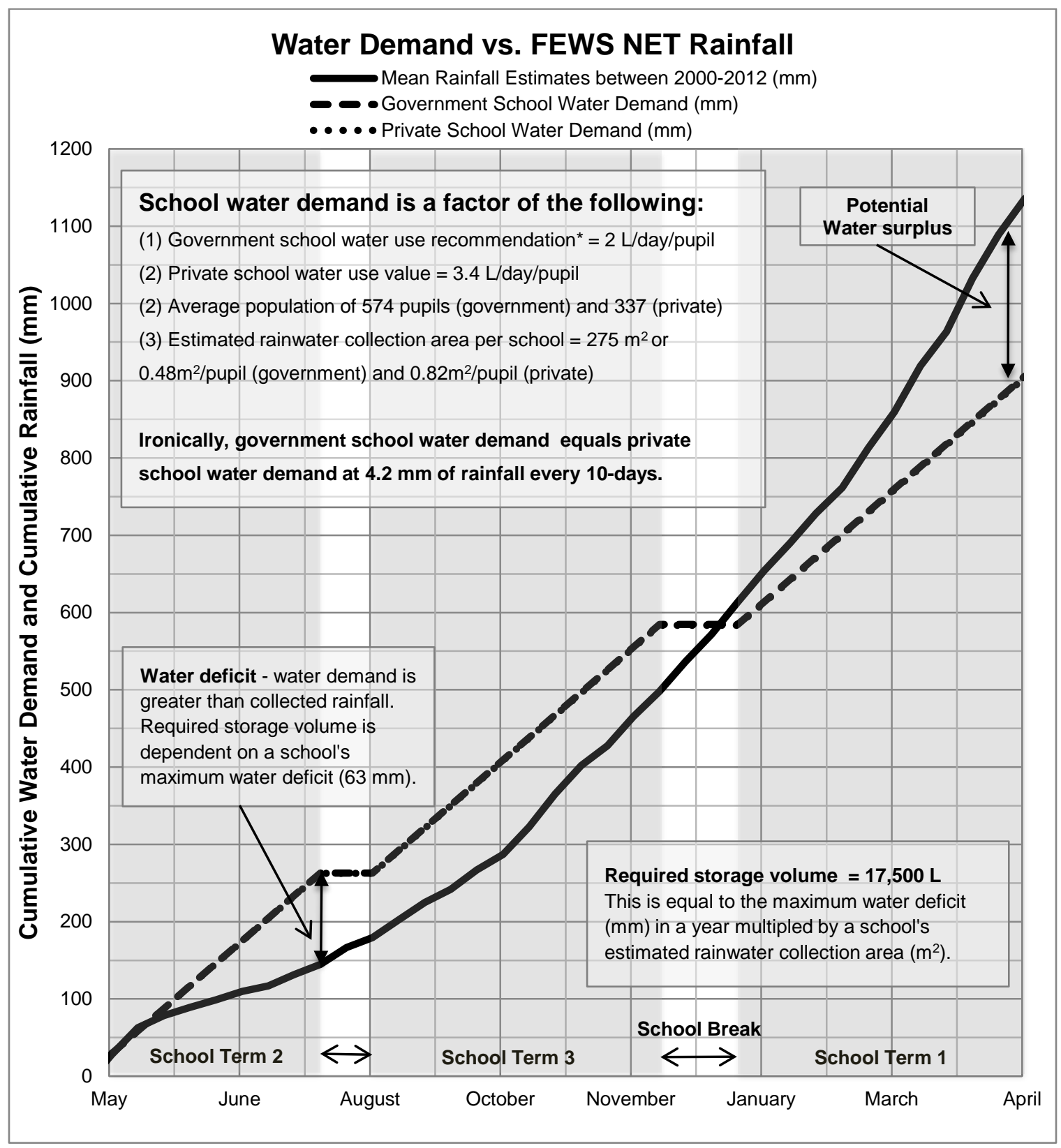

3.13: Rakai District rainfall estimates (2000-2012) and school water demand plotted to determine a school's required storage volume for the largest water deficit experienced in one school year. 
Ironically, it was seen that both government and private schools 10-day water demand with equal collection areas was equal at $4.2 \mathrm{~mm}$ of rainfall depth. Since both government and private schools have school breaks at the same time of year (July August, December), water demand at these times was theoretically stagnant. To determine the required storage volume for government and private schools to provide given water use values, the maximum water deficit seen in a year (66 $\mathrm{mm})$ is multiplied by a school's estimated rainwater collection area $\left(275 \mathrm{~m}^{2}\right)$.

$$
\text { School water demand }[\mathrm{mm}]=\frac{\text { Water use per school }\left[\frac{\frac{L}{\text { day }}}{\text { pupil }}\right]}{\text { Collection area per school }\left[\frac{\mathrm{m}^{2}}{\text { pupil }}\right]}
$$

Water deficit $[\mathrm{mm}]=$ Water demand $[\mathrm{mm}]-$ Rainfall estimate $[\mathrm{mm}]$

Required storage volume $[L]=$ Maximum water deficit $[\mathrm{mm}] \times$ Collection area $\left[\mathrm{m}^{2}\right]$

Since water demand and collection areas at both school types are equal, the maximum water deficit values are also equal, with both school types requiring 17,500 L of storage volume. Comparing the existing average rainwater storage volumes at government $(10,000 \mathrm{~L})$ and private $(16,000 \mathrm{~L})$ schools sampled, we see that the required storage volume is not much greater than schools current infrastructure. If a schools water demand and collection areas were to increase, the required storage volume for rainwater collection must also be improved.

\subsection{Water and Sanitation Assessment Tool}

A relationship among government and private schools' water and sanitation condition was acknowledged by evaluating schools' water use and pupil to latrine stance ratios. With recommended water use values of $2 \mathrm{~L} / \mathrm{day} /$ pupil and a pupil to latrine stance ratio of $40: 1$, primary schools are identified by meeting recommended values or not. By placing schools' daily water use on the $x$-axis of the assessment tool and pupil to latrine stance ratio on the $y$-axis, users are able to evaluate schools' respective water use and 
latrine stance coordinates (see Figure 3.14). With dashed lines representing recommended values, four distinct quadrants are created to assess schools' water and sanitation condition.

In Quadrant I, we see neither of the recommended water use or pupil to latrine stance values has been met. In Quadrant II, we identify schools as not meeting recommended water use values, but meeting the pupil to stance ratio recommendation. In Quadrant III, schools have met recommended water use values, but fail to provide an adequate number of latrine stances for pupils. In Quadrant IV, both recommended values have been met. We would like to see all schools in or moving toward the direction of Quadrant IV in the assessment tool.

Before placing schools into quadrants, we add two data indicators which help distinguish primary schools' social characteristic. The first indicator is school type, which is done by color-coding points on the chart for both government and private schools. With black dots representing government schools and white dots representing private schools, we are able to easily identify schools' representation. The second indicator is a pupil to teacher ratio, which normalizes school size and pupil population in our study. With a pupil to teacher ratio determining the size of each point on the chart, schools become even more distinguishable from one another. With given water use and latrine use recommendations, as well as indicators in the assessment tool, charting and analyzing data points becomes a valuable tool for comparing schools' water and sanitation condition.

In our analysis, $47 \%$ of all schools sampled failed to meet both the recommended water use and latrine stance value. The majority of government schools were identified here in Quadrant I (34\%) or Quadrant II (59\%), signifying they have a difficult time providing recommended water use values per pupil. Half of all private schools sampled were able to provide either the recommended water use value (50\%) or pupil to latrine stance ratio (55\%), with many private schools (35\%) meeting both. Only two government schools (7\%) were able to meet both of these recommended values. For a complete list of school quadrant data, please refer to the Appendices of this report. 


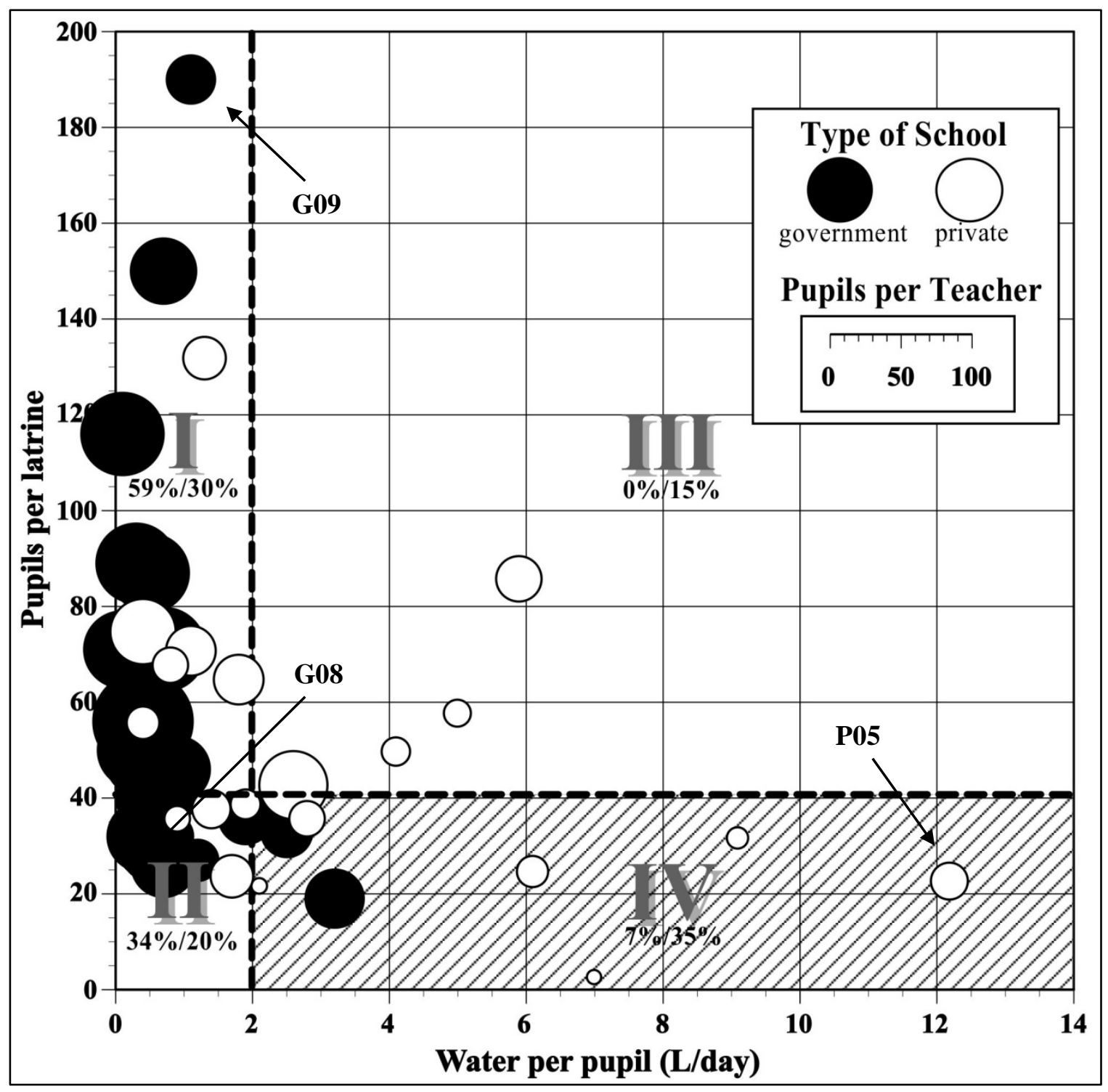

Figure 3.14: Identifying relationships among Rakai District primary schools using the Water and Sanitation Assessment Tool. 


\section{Discussion}

\subsection{School Relationships and Outliers}

Looking at the results of our water and sanitation assessment tool (see Figure 3.14); we are able to identify school relationships and recognize outliers in the study. Schools discussed have been chosen for their unique identity in the assessment tool and greatly help us gage appropriate water and sanitation conditions.

The first school we identify is P05 in Quadrant IV. Among all schools sampled, this rural based private school had the highest water use values of $12.2 \mathrm{~L} /$ day per pupil and the third lowest pupil to latrine stance ratio of $22: 1$. With a pupil to teacher ratio of $26: 1$, this school was able to efficiently maximize school resources for pupils. Prior to visiting P05, the author and colleague were well aware of the school's high standard of education, community outreach partnerships, and donor activity. While funding sources were never solicited during the study, it was known that P05 had a large funding source from the Catholic Church and partial funding from the Uganda government's UPE program. Water sources included three $10,000 \mathrm{~L}$ rainwater tanks and two 20,000 L underground concrete storage tanks, providing water to a privately operated piped water supply system. With a school truck also available, school officials recognized their ability to collect water from nearby lakes and rivers when water storage was low. With a high percentage of boarding students at the school, the availability and quantity of water distributed were both important factors in continued operation. Interview responses concerning the schools water and sanitation successes, challenges, and improvements indicated the school, however, was still trying to collect more rainwater and improve its piped water supply system. The school also recognized a common connection between water and sanitation, mentioning that "addressing water problems will improve sanitation."

The second school we identify is in Quadrant I. Schools in this quadrant had a difficult time meeting either of the recommended water use and pupil to latrine stance values. Here, school G09 is a government school located in an urban setting of Rakai District. It 
has a pupil to teacher ratio of 34:1, a water use value of $1.1 \mathrm{~L} /$ day per pupil, and pupil to latrine stance ratio of 190:1. School water use was seen to be dependent on the city's publicly operated piped water supply system with an option to buy from local water sellers. School latrine use is of more concern in this case, since the number of students per latrine is so great. It is difficult to imagine 190 pupils using on one latrine stance, and how quickly those latrine pits must fill up. The school's latrine source included 5 simple pit latrine stances; however, once full, these existing pits were mechanically emptied due to insufficient room to construct new latrines. During the interview period, the school acknowledged it was building several more pour flush toilets for teachers, though construction had not yet been completed.

The last school we recognize is a common amongst most Rakai District primary schools sampled. At government school G08 in Quadrant II, we choose a school which helps us evaluate common schools' water and sanitation conditions. With a majority of all schools falling into Quadrants I (47\%) and II (29\%) of the assessment tool, schools here provide a representative picture of the challenges faced and improvements needed. School G08 has a population of 389 pupils and a pupil to teacher ratio of 32:1. It has a water use value of $0.8 \mathrm{~L} /$ day per pupil and a pupil to latrine stance ratio of 26:1, though latrines are in poor structural condition. The school has two metallic rainwater tanks; however, both leaked and were no longer in working condition. Other water sources include a shared community borehole and an unprotected shallow well, which are both located less than $1 \mathrm{~km}$ from the school. All school latrines are ventilated, though some doors are missing on some of the structures, and there is rarely water or soap for handwashing. While latrine pit covers were said to be available, none were seen upon our visit to the latrine. During the interview period, teachers identify that one sanitation success of the school has been to educate pupils on improved sanitation and hygiene practices, and that few sicknesses have occurred because of poor sanitation. The reference and relationship among water and sanitation was once again addressed by a school teacher, quoting that "if water is available, then sanitation can be improved." 


\subsection{Observed WASH Technologies}

The term water, sanitation, and hygiene, or WASH, is well known in Uganda and in the international development community. These are all important factors in identifying, measuring, and improving community health challenges in Uganda, as well as in the schools we sampled. The following section addresses commonly observed WASH technologies used in communities and primary schools within Rakai District. This section provides an overview of commonly used water supply sources including open sources, shallow wells, boreholes, rainwater tanks, and piped water supply systems. In regards to sanitation, latrine types have been addressed as well as a sanitation project completed by the author of this study. Finally, hand-washing methods and questions used by Rakai District health workers to assess sanitation and hygiene have been addressed.

\subsubsection{Common Water Sources}

With numerous bodies of water, rolling hills, and sufficient rainfall in most of the country, people have commonly relied upon open sources for daily water use needs. As seen in this study's water and sanitation assessment of Rakai District primary schools, open sources were a common water source for primary schools' water needs (55\%). Open sources include unprotected bodies of surface water including springs, rivers, lakes, ponds, and wetlands which serve people and animals alike. These sources are known to be dirty and minimizing use from them is desired. While open sources are not preferred among users, communities and schools often resort to them when there is no other option for water collection. In our study, open sources were often the last alternative schools resorted to when rainwater tanks were dry, a borehole broke, or there was no water at the tap.

Shallow wells are another water source used by Rakai District primary schools (28\% government, $15 \%$ private). While language differences may incorrectly identify shallow wells as shallow ponds, or even open sources, they are more closely related to a closed 
borehole. Shallow wells in Uganda often use the same mechanical water lifting system as boreholes; however, the distance to obtain sufficient groundwater is much less. In theory, shallow wells are termed when drillers reach the groundwater table before a depth of $30 \mathrm{ft}$. During teacher interviews, it was important to understand the definition of a shallow well before teachers claimed they did or did not use them.

Boreholes in Uganda are most common in northern parts of the country. With drier weather, less rainfall, and minimal access to a piped water supply, obtaining groundwater here from boreholes becomes a very important task. In this study, borehole use was common amongst Rakai District primary schools (34\% government, $40 \%$ private). Boreholes are typically defined as a mechanized system to obtain water from a groundwater depth below $30 \mathrm{ft}$. This is done by drawing water by manually pumping and lifting water through a pipe. While maintenance of boreholes falls onto the responsibility of local governments and water offices, community members and schools have difficulty receiving repair service and resort to less attractive open water sources.

The use and promotion of rainwater collection is at the forefront of many Ugandan water initiatives. As mentioned previously in the report, Uganda receives ample rainfall which is used to alleviate many water quantity and quality challenges. Most rainwater technologies are very appropriate for both urban and rural communities, and can be designed to catch and store water for a variety of conditions and quantities. Rainwater technologies used in Uganda include heavy plastic tanks, metallic tanks, ferro-cement tanks, rain jars, below grade storage pits, and a number of other low-tech collection methods. Technologies can be so simple as to collect water in kitchen pots or plastic buckets, which many people use to increase the amount of water being collected. After an initial cost to implement these systems, water collection becomes relatively free and possibly even an income with water sales. Sizes of tanks vary according to water needs with tanks ranging from $20,000 \mathrm{~L}$ to $60 \mathrm{~L}$. Rainwater collection is dependent on a specific location's respective rainfall amount, catchment area (i.e. roof), collection system (i.e. gutters), and storage container (i.e. tank). Rainwater collection was the most common response as to how to improve schools' water conditions. 
The last water source commonly seen in Uganda is the piped water supply system. Most of Uganda's piped water is managed by the National Water and Sewerage Corporation (NWSC), which owns and operates all of Uganda's public piped water supply systems. In Rakai, piped water is made available by pumping filtered water from a local lake and supplying that through a system of metered taps in town. Tap stands may be found in public places and shared by a group of users, or located within a private household compound. Piped water can also be delivered to local schools if the connection fee can be paid, and the source is not too far away. Public piped water supply systems often rely on electricity, which is not too common or consistent in rural Rakai communities. Private schools in Rakai had a higher percentage of access to piped water supply systems, often because they were able to pay for the connection fee.

\subsubsection{Common Latrine Sources}

Ventilated pit latrines were the most common form of toilets in the primary schools visited in Rakai District (90\% government, 55\% private). Most of these were marginally "improved", however, because most were in very poor structural condition and shared amongst many users. At schools, most latrines were separated between girls, boys, and teachers, though, the number of latrine users per stance was often well above the recommended value of 40:1 (66\% government, 50\% private). Squatting over a hole in a pit latrine with very limited access to water made it very hard to keep things clean, especially when you added thirty, forty, or fifty youth users to a stance.

Pit latrines usually consisted of one large hand-dug, unlined pit, with two to three stalls, and one ventilation pipe with minimal or no screening. There was sometimes a urinal wall for boys on the outside of a latrine stall which drained into the ground or an underground soak pit. Super-structures were often built with locally made clay fired bricks and plastered with concrete. The floor of most latrines was concrete with a small rectangular latrine pit opening. In less-developed areas, entire structures may be built from wood and mud with a much shallower pit. The roof of the latrine was often corrugated aluminum sheeting or grass thatch depending on its outside structure. Rectangular wooden latrine pit covers were designed to keep flies away and minimize 
the spread of germs. This was done by covering a hole with a flat wooden plank attached to a narrow wooden handle. Unfortunately, most households and schools did not use this cover consistently though it was available. Toilet paper was easy to come by in most general stores, though not shared among the users of a latrine. There was a general understanding each would bring their own toilet paper and share that latrine with a limited number of people. Schools followed this rule and most required students to bring toilet paper for their latrine use.

The use of ecological sanitation, or composting latrines, wet or dry, was improving in Rakai District. Composting latrines were often built in areas which had a high water table, and therefore, raised pits were acceptable and necessary. Most composting latrine users were well aware of using dried human waste as a fertilizer. In fact, with the help of the Red Cross, Peace Corps, and two local masons, the author helped to manage the construction of a 2-stance, 4-chamber composting latrine at a local primary school and orphanage. This project was completed over a six month span which incorporated proposal writing, planning and scheduling, budgeting, education, material purchases, construction, quality control, and maintenance. The project was completed at an orphanage school on the shores of Lake Victoria and aimed to improve the access to sanitation for 300 pupils.

While the use of flush toilets was not common in Rakai District primary schools, they did exist at a few of the schools studied. In general, flush toilets are more common in bigger cities and at hotels, hospitals, government buildings, and international organization offices. They cater to a wealthier population, and are feasible because water supply is generally higher at these places. Unfortunately, rural schools in Rakai did not meet these conditions. With very few wastewater treatment plants in Uganda, most flush toilets drained to private septic tanks, which was the case at two private schools studied. While children were not the intended users for a flush or pour-flush toilet, teachers and international visitors were welcome to use such facilities. Children often had no quarrels with using schools' pit latrines. 


\subsubsection{Hygiene and Hand-washing}

Hand-washing is another concern among Rakai District communities and primary schools. While people in Rakai did know to wash their hands before eating, and after using the toilet, the challenge was to simply make the practice more accessible and affordable. At government schools, water for hand-washing was often not made available (41\%), compared to private schools which almost always provided water for hand-washing (95\%). Hand-washing with soap use was a less common practice at both government schools (7\%) and private schools (50\%). As more rainwater tanks are constructed in the country, the availability of water for hand-washing has improved, and in theory, sanitation and hygiene will improve as well.

Besides increasing water supply, hand-washing practices and use has been made more available by the construction locally built hand-washing stations, or "tippy taps". A tippy tap is a small $5 \mathrm{~L}$ container used to store water for the sole purpose of hand-washing. The design does not require mechanization, and can be made out of inexpensive and locally available materials, including three sturdy sticks, string, and a small storage container with a few nail holes punched in it.

Other requirements Rakai District community health inspectors used to determine if a household provided access to improved sanitation and hygiene practices were of the following. While these questions were used to assess household sanitation, they have also been adapted for school sanitation and hygiene purposes. These questions were not asked during this study's data collection phase; however, they did provide the author with an understanding of how local health inspectors assessed sanitation and hygiene.

\section{Sanitation and hygiene checklist adopted from Rakai District health inspectors:}

$\checkmark$ Does the school have a clean and working latrine?

$\checkmark \quad$ Is there an area to wash your hands with soap and water nearby?

$\checkmark$ Is the latrine hole covered to minimize fly attraction?

$\checkmark$ Does the school have a clean and orderly compound?

$\checkmark$ Does the school have a rubbish pit or area for waste disposal? 
$\checkmark$ Does the school use a drying rack (i.e. raised wooden platform) for dishes?

$\checkmark$ Does the school have and use a kitchen? Is it separated from other buildings?

$\checkmark$ Does the (boarding) school have a separated bathing shelter?

$\checkmark$ Does the school keep the grass and bush short to minimize breeding grounds for mosquitos?

\subsection{Recommendations}

\subsubsection{Prioritizing Water and Sanitation}

This report's research recommendations have been developed to improve water and sanitation conditions in Rakai District primary schools. Recommendations incorporate an assessment of existing water and sanitation infrastructure and teacher interview responses. This report acknowledges that water and sanitation in Rakai District primary schools can be improved if local policy makers, teachers, parents, and pupils prioritize water and sanitation needs. While minimal funding for water and sanitation projects often limits what these schools, community members, government offices, and humanitarian organizations implement, local stakeholders must support the well-being of pupils by working together to provide more improved water and sanitation sources. Vast social complexities which slow down the process of increasing access to improved water and sanitation sources often include land ownership rights, maintenance of existing water and sanitation systems, and political corruption. These challenges must be met, and financial consideration and honest accountability must be a priority among all in any design recommendation.

\subsubsection{Addressing Rainwater Collection}

There are very few people in Rakai District which would tell you an additional rainwater tank would not improve water access. Rainwater use is seen as an improved water source by MDG authors and teachers in Rakai District easily recognized this potential. As seen in the qualitative results section for water improvements, many teachers (29\% 
government, $43 \%$ private) recommended the increased use of rainwater collection as a strategy to improve schools' water collection and distribution.

School visits allowed the author to understand school water availability and why technologies were working or not. In regards to schools' rainwater collection efforts, it was seen that many rainwater tanks were present, however, not in operational condition. In this study, approximately $90 \%$ of all private school rainwater tanks were working, while only $65 \%$ of existing government school rainwater tanks worked. Often, a simple tank repair, gutter replacement, or spigot tap was needed to restore full collection efforts and storage capacity. In Uganda, rainwater tanks were often associated as gifts from international agencies and donor groups, which were no exception in both the government and private primary schools visited. This donation often led to schools believing someone else would fix the tank for them. While giving rainwater tanks did not promote a sense of ownership or problem solving among schools, it undoubtedly did increase water access and proved a value for additional rainwater collection investment.

Rainfall estimates in Rakai District were then compared to schools' existing water demand. While estimations were made for schools' assumed collection area (i.e. surface area of a school roof) and collection rate (100\%), the storage volume required to distribute a recommended water use value of 2 L/day for given rainfall estimates was calculated. With a determined storage volume of $17,500 \mathrm{~L}$ required for government and private schools, schools sampled are able to calculate their additional rainwater storage needed. It is recommended that schools repair existing tanks first and then revise calculations if they wish to supply more than 2 L/day per pupil population. Researchers will also be able to design more accurate rainwater collection systems if a school collection area and rate of collection were measured. Cost estimations for rainwater tanks can be determined for a calculated for an amount of storage volume required.

Further analysis of USGS FEWS NET rainfall estimates in Uganda and Rakai District may be of interest to researchers, policy makers, and development organizations to identify the reliability of current rainwater collection systems. Localized rainfall estimations and seasonal trends should be understood to help schools realize how to best utilize rainwater catchment and storage technologies. By predicting future rainfall 
quantities and trends, the required storage volume per school for an amount of collected rainfall can be calculated to help local governments and funders make financial decisions regarding the implementation of additional rainwater use technologies.

\subsubsection{Assessment Tool Variables}

In this study, we evaluated water and sanitation infrastructure at 49 primary schools in Rakai District and compiled teacher interview responses regarding schools' water and sanitation successes, challenges, and improvements. The water and sanitation assessment tool was developed to map schools' performance in four water and latrine use quadrants. The tool could be applied in further water and sanitation development projects throughout the country, particularly in schools or communities which wish to assess existing water and sanitation infrastructure. Using chosen indicators in the study, including school type (government or private) and pupil to teacher ratios, we were able to more thoroughly analyze schools' water and sanitation condition. Recommended water and sanitation values could be adapted to evaluate other schools in various regions in Uganda and elsewhere.

Additional indicators in this assessment could also include school location, which would be determined by the shape of each chart point. For example, a white box would indicate a private school in Kooki County, Rakai District, while a black circle would identify a government school in Kyotera County. By recognizing location in the assessment tool, we are able to help researchers and policy makers compare water and sanitation conditions at a regional level. With increased data collection points at a specific location, a time-series of data could help distinguish a school's movement from one quadrant to another. Including data from around the World, or from one District in Uganda to another, could potentially provide useful comparisons of existing water and sanitation condition. Other variables which were not included in the assessment tool, but were discussed among authors, include the volume of rainwater used or collected at a school, the type of water sources available, and the distance from a water source (i.e. lake). 


\section{Conclusions}

This study was aimed at evaluating water and sanitation infrastructure and condition in government and private primary schools. This comparison was based on school type, where researchers acknowledged technologies being used in local primary schools, and what teachers identified as water and sanitation successes, challenges, and potential improvements. The report was written to help Rakai District and interested parties assess water and sanitation conditions in local communities. Researchers chose to evaluate water and sanitation in primary schools because it is where the author's organization targeted development efforts, and where data did not exist.

The author and Ugandan colleague gathered information through on-site teacher interviews visiting a total of 49 primary schools in a 10-day period. Out of the 49 primary schools visited, 29 were government schools and 20 were private. Interview methods were semi-structured and recorded through note taking and photo record. The confidentiality of schools was maintained throughout the study and intended to give schools an opportunity to share concerns and challenges concerning water and sanitation.

The study found that government schools relied more on rainwater collection technologies (94\%), while private schools relied on electrical piped water supply systems (60\%). Policy on government schools water sources was not studied in detail, but water sources and sanitation trends were identified in government schools sampled. Water use in government schools was significantly less per pupil, with an average use of 0.7 L/day compared to 3.4 L/day in private schools. Distances to school water sources, including boreholes, shallow wells, and open sources, were on average $1 \mathrm{~km}$ away from both government and private schools. Rainwater tanks and a piped water supply system were always located at the school, so the distance to these sources was negligible. Latrine type and pupil to latrine stance values were also of interest to researchers. A majority of government schools (90\%) and private schools (55\%) relied on ventilated improved pit latrines. Pupil to latrine stance values in the study ranged as high as 190:1 to $2: 1$, indicating a vast difference in sanitation and hygiene conditions among schools 
studied. The average pupil to latrine stance ratio of government schools was 56:1, with private schools slightly less at 48:1.

In this study, a government/private water and sanitation assessment tool was developed to characterize schools into four water and sanitation quadrants. Quadrants were created by identifying the World Health Organization's and locally recommended water use values of 2 L/day and pupil to latrine stance ratio of 40:1. With daily water use and pupil to latrine stance ratios on the axes of the assessment tool bubble chart, each school's respective chart coordinates placed them into one of four quadrants. School indicators including school type (by color) and a pupil to teacher ratio (by size) helped distinguish schools from one another in the relationship. In this analysis, the majority of all schools studied (47\%) failed to meet both the recommended water and latrine use values, with only 9 schools (18\%) meeting both. In general, government schools had a more difficult time providing an adequate water supply with only two schools (7\%) meeting the recommended value of $2 \mathrm{~L} /$ day. With smaller pupil populations and increased water availability, half of all private schools (50\%) were able to provide this value. In regards to schools' pupil to latrine stance ratios, nearly half (47\%) of all schools were able to meet the recommended value of $40: 1$.

Teacher interview responses also provided researchers with important characteristics of schools' water and sanitation successes, challenges, and potential improvements. Government schools' biggest success and challenge dealt with rainwater collection (40\%) and low quantity of water provided to pupils (21\%), respectively. Other government school water challenges included difficulties with neighboring communities (17\%) and the distance and/or time to collect water (15\%). Out of the 20 private schools interviewed, the majority (24\%) identified access to a piped water supply system as their biggest water success. The most common water challenges among private schools were the high costs of supplying water (20\%) and the lack of small water storage containers (20\%). The most common water improvement response from government (27\%) and private schools (28\%) was to address rainwater collection needs. Water treatment (14\%) and protecting water sources from community members (16\%) were common responses among government schools. Private schools identified obtaining and/or improving a piped water supply system (17\%) as a potential water improvement. 
The least common response among schools was a desire to reach out to local community members and parents to improve water conditions for all.

In regards to sanitation, government schools showed a high interest (28\%) in increasing the number of latrine stances. WASH education was the second most identified response by government schools (22\%) and the most common response of private schools (24\%). The biggest sanitation challenge mentioned by both government (27\%) and private schools (28\%) was a minimal amount of latrine stances. The smell of latrines was not seen as an issue at most schools. The construction or repair of latrines was identified by both government (38\%) and private (33\%) schools as a desired sanitation improvement. While private school responses also focused on improving water supply (18\%), waste disposal methods (15\%), and educating pupils on healthy sanitation practices (12\%), responses from government schools were almost equally distributed.

Methods used to assess water and sanitation infrastructure in Rakai District primary schools has provided researchers with a quantitative and qualitative understanding of existing technologies and impressions. It is important to evaluate school water and sanitation conditions with an interdisciplinary approach and understand that a technical solution will not solely put an end to water and sanitation challenges. There are many factors which affect a school's ability to provide improved water and sanitation sources.

Future work in this field would include further analysis of rainfall estimates using historical data and rainfall estimates. Through USGS FEWS NET rainfall estimates, it was calculated that an average of $17,500 \mathrm{~L}$ of rainwater storage was needed to provide schools with a minimum water use value of 2 L/day. With teachers interested in improving rainwater collection, further research could help calculate more accurate solutions to improving water distribution at each school. The use and development of the water and sanitation assessment tool should be addressed in future work and incorporated into more studies in Uganda and elsewhere. The inclusion of school location and additional data collection over time could help analyze school trends in water and sanitation infrastructure development. 
While this study was not intended to bring schools money or immediate infrastructure improvements, it did provide schools with an opportunity to share thoughts and concerns about school water and sanitation. Assessment results provide the local Rakai District government offices with current data regarding primary schools' water and sanitation needs. The assessment of water and sanitation conditions may aid local policy makers and other humanitarian organizations, including the Red Cross, in their planning, implementing, and managing of future water and sanitation projects. While many organizations and governments look to enhance access to improved water and sanitation sources at the household level, it is also important to recognize that schools must also meet this obligation. With this report, we hope to recognize the need to promote access to improved water sources and sanitation in Ugandan primary schools. 


\section{Bibliography}

1. Central Intelligence Agency [Internet]. 2012. The World Factbook - Uganda; [updated weekly, cited 2012 Feb 18]. Available from:

https://www.cia.gov/library/publications/the-world-factbook/geos/ug.html

2. World Health Organization and United Nations Children's Fund [Internet]. 2012. Joint Monitoring Programme: Progress on Drinking Water and Sanitation; 2012 Update. [Cited Feb 2012]. Available from: http://www.who.int/water sanitation health/publications/2012/imp report/en/inde $\underline{x . h t m l}$

3. Rakai District Local Government. 2007. 2002 Population and Housing Census Analytical Report.

4. Rakai District Local Government. 2010. Report on Rakai District. MDG Localisation.

5. Uganda Bureau of Statistics (UBOS) and Macro International Inc. 2007. Uganda Demographic and Health Survey 2006. Calverton, Maryland, USA: UBOS and Macro International Inc.

6. Mapsof.net [internet]. 2012. Available from: http://mapsof.net/map/un-uganda.

7. Government of Uganda [Internet]. 2012. Ministry of Education and Sports; [updated]. Available from: http://www.education.go.ug/.

8. Bernard, Russel H. 2006. Interviewing: Unstructured and Semistructured. Research Methods in Anthropology, 4th ed. Qualitative and Quantitative Approaches. Lanham (MD): AltaMira Press. p. 210-250.

9. Strauss and Corbin. 1998. Coding Procedures. Basics of Qualitative Research; Techniques and Procedures for Developing Grounded Theory, 2nd ed. Sage Press. p. 106-113.

10. Researchware [internet]. 2012. HyperRESEARCH; [updated 2011 June 2, cited 2012 Jan 16]. Available from: http://www.researchware.com/products/hyperresearch.html

11. United States Geological Survey [Internet]. Famine Early Warning Systems Network; [updated 2011 June 20, cited 2012 April 2]. Available from: http://earlywarning.usgs.gov/fews/ 


\section{Appendices}




\section{A. Summary of Quantitative Data by School Type}

\begin{tabular}{|l|c|c|}
\hline School Identification Data & $\begin{array}{c}\text { Priv. } \\
\text { schools }\end{array}$ & $\begin{array}{c}\text { Govt. } \\
\text { schools }\end{array}$ \\
\hline Number of schools studied & 20 & 29 \\
\hline Total number of pupils & 6,737 & 16,640 \\
\hline Total number of boys & 3,192 & 8,104 \\
\hline Total number of girls & 3,545 & 8,536 \\
\hline Total number of teachers & 258 & 377 \\
\hline Average number of pupils & 337 & 574 \\
\hline Max number of pupils & 817 & 957 \\
\hline Min number of pupils & 85 & 258 \\
\hline Median number pupils & 340 & 556 \\
\hline Standard deviation of pupils & 194 & 186 \\
\hline Average boy to girl ratio & $9: 10$ & $9: 10$ \\
\hline Average pupils to teacher ratio & $26: 1$ & $44: 1$ \\
\hline
\end{tabular}

\begin{tabular}{|l|c|c|c|c|c|}
\hline Water Sources & $\begin{array}{c}\text { Rain- } \\
\text { water } \\
\text { Tank }\end{array}$ & $\begin{array}{c}\text { Shallow } \\
\text { well }\end{array}$ & Borehole & $\begin{array}{c}\text { Piped } \\
\text { water } \\
\text { supply }\end{array}$ & $\begin{array}{c}\text { Open } \\
\text { source }\end{array}$ \\
\hline Private Schools (n = 20) & & & & & \\
\hline Total number of sources & 18 & 3 & 8 & 12 & 13 \\
\hline Average distance to source [km] & 0.0 & 1.5 & 0.5 & 0.0 & 1.9 \\
\hline Source availability use (\%) & $35 \%$ & $15 \%$ & $40 \%$ & $60 \%$ & $55 \%$ \\
\hline Government Schools (n = 29) & & & & & \\
\hline Total number of sources & 59 & 11 & 11 & 4 & 22 \\
\hline Average distance to source [km] & 0.0 & 1.8 & 1.2 & 0.0 & 1.3 \\
\hline Source availability use (\%) & $93 \%$ & $28 \%$ & $34 \%$ & $14 \%$ & $55 \%$ \\
\hline
\end{tabular}




\begin{tabular}{|l|c|c|}
\hline Rainwater Storage and Use & $\begin{array}{c}\text { Priv. } \\
\text { schools } \\
\text { (n=20) }\end{array}$ & $\begin{array}{c}\text { Govt. } \\
\text { schools } \\
\text { (n=29) }\end{array}$ \\
\hline Total number of working tanks & 17 & 38 \\
\hline Percentage of working tanks (\%) & $94 \%$ & $64 \%$ \\
\hline Average tank capacity [L] & 16,182 & 9,526 \\
\hline Average storage per pupil [L] & 48 & 17 \\
\hline Water Use per School and Pupil & $\begin{array}{c}\text { Priv. } \\
\text { schools } \\
\text { (n=20) }\end{array}$ & $\begin{array}{c}\text { Govt. } \\
\text { schools } \\
\text { (n=29) }\end{array}$ \\
\hline Average water use per school [L/d] & 839 & 389 \\
\hline Max water use per school [L/d] & 3000 & 1440 \\
\hline Min water use per school [L/d] & 100 & 30 \\
\hline Median water use per school [L/d] & 550 & 300 \\
\hline Average water use per pupil [L/d] & 2.8 & 0.7 \\
\hline Max water use per pupil [L/d] & 9.1 & 3.2 \\
\hline Min water use per pupil [L/d] & 0.0 & 0.1 \\
\hline Median water use per pupil [L/d] & 2 & 0.5 \\
\hline
\end{tabular}

\begin{tabular}{|l|c|c|c|c|}
\hline No. of Latrine Stances & $\begin{array}{c}\text { Simple } \\
\text { pit }\end{array}$ & VIP & $\begin{array}{c}\text { Compost } \\
\text { ing }\end{array}$ & $\begin{array}{c}\text { Pour- } \\
\text { flush }\end{array}$ \\
\hline Private schools (n=20) & 49 & 162 & 6 & 1 \\
\hline Government schools (n=29) & 91 & 289 & 8 & 4 \\
\hline
\end{tabular}

\begin{tabular}{|l|c|c|}
\hline Latrine Stance Ratios & $\begin{array}{c}\text { Priv. } \\
\text { schools } \\
\text { (n=20) }\end{array}$ & $\begin{array}{c}\text { Govt. } \\
\text { schools } \\
\text { (n=29) }\end{array}$ \\
\hline Average stances per school & 10 & 13 \\
\hline Average pupil to stance ratio & $48: 1$ & $56: 1$ \\
\hline Max pupil to stance ratio & $131: 1$ & $190: 1$ \\
\hline Min pupil to stance ratio & $2: 1$ & $19: 1$ \\
\hline Median pupil to stance ratio & 40 & 45 \\
\hline
\end{tabular}




\begin{tabular}{|l|c|c|}
\hline Latrine Questions & $\begin{array}{c}\text { Priv. } \\
\text { schools } \\
\text { (n=20) }\end{array}$ & $\begin{array}{c}\text { Govt. } \\
\text { schools } \\
\text { (n=29) }\end{array}$ \\
\hline Separate for boys/girls & $85 \%$ & $90 \%$ \\
\hline Separate for pupils/teachers & $80 \%$ & $83 \%$ \\
\hline Latrines have doors & $70 \%$ & $66 \%$ \\
\hline Latrine conductive for use & $90 \%$ & $97 \%$ \\
\hline Covered latrine pit & $15 \%$ & $0 \%$ \\
\hline Water for handwashing & $95 \%$ & $41 \%$ \\
\hline Soap for handwashing & $50 \%$ & $7 \%$ \\
\hline
\end{tabular}




\section{B. Water and Sanitation Assessment Tool Quadrant Summary}

\begin{tabular}{|c|c|c|c|c|c|}
\hline \multicolumn{2}{|c|}{ Quadrant Summary } & $\begin{array}{c}\text { Quad I } \\
(x<2, y>40: 1)\end{array}$ & $\begin{array}{c}\text { Quad II } \\
(x<2, y<40: 1)\end{array}$ & $\begin{array}{c}\text { Quad III } \\
(x>2, y>40: 1)\end{array}$ & $\begin{array}{c}\text { Quad VI } \\
(x>2, y<40: 1)\end{array}$ \\
\hline \multicolumn{2}{|c|}{ Private school totals } & $6(30 \%)$ & $4(20 \%)$ & $3(15 \%)$ & $7(35 \%)$ \\
\hline \multicolumn{2}{|c|}{ Government school totals } & 17 (59\%) & $10(34 \%)$ & $0(0 \%)$ & $2(7 \%)$ \\
\hline \multicolumn{2}{|c|}{ All school totals } & $23(47 \%)$ & $14(29 \%)$ & $3(6 \%)$ & $9(18 \%)$ \\
\hline School Code & $\begin{array}{c}\text { Pupil to } \\
\text { Teacher Ratio }\end{array}$ & Quad I & Quad II & Quad III & Quad VI \\
\hline P01 & 46 & & $\mathrm{X}$ & & \\
\hline P02 & 35 & & $X$ & & \\
\hline P03 & 23 & & $\mathrm{X}$ & & \\
\hline P04 & 21 & $\mathrm{X}$ & & & \\
\hline P05 & 26 & & & & $\mathrm{X}$ \\
\hline P06 & 20 & & & $\mathrm{X}$ & \\
\hline P07 & 15 & & & & $\mathrm{X}$ \\
\hline P08 & 22 & & & & $\mathrm{X}$ \\
\hline P09 & 10 & & & & $X$ \\
\hline P10 & 48 & & & & $\mathrm{X}$ \\
\hline P11 & 35 & & $\mathrm{X}$ & & \\
\hline P12 & 32 & & & $X$ & \\
\hline P13 & 18 & $\mathrm{X}$ & & & \\
\hline P14 & 30 & & $\mathrm{X}$ & & \\
\hline P15 & 19 & & & $\mathrm{X}$ & \\
\hline P16 & 11 & & & & $\mathrm{X}$ \\
\hline $\mathrm{P} 17$ & 30 & $\mathrm{X}$ & & & \\
\hline P18 & 25 & & & & $\mathrm{X}$ \\
\hline P19 & 25 & & $\mathrm{X}$ & & \\
\hline $\mathrm{P} 20$ & 27 & $\mathrm{X}$ & & & \\
\hline G01 & 70 & & $X$ & & \\
\hline
\end{tabular}




\begin{tabular}{|c|c|c|c|c|}
\hline G02 & 58 & & $X$ & \\
\hline G03 & 54 & & $\mathrm{X}$ & \\
\hline G04 & 56 & & X & \\
\hline G05 & 59 & & $\mathrm{X}$ & \\
\hline G06 & 54 & & $\mathrm{X}$ & \\
\hline G07 & 41 & & X & \\
\hline G08 & 32 & $X$ & & \\
\hline G09 & 34 & & X & \\
\hline G10 & 29 & $X$ & & \\
\hline G11 & 46 & & X & \\
\hline G12 & 36 & $X$ & & \\
\hline G13 & 41 & & & X \\
\hline G14 & 39 & & X & \\
\hline G15 & 25 & $\mathrm{X}$ & & \\
\hline G16 & 50 & $X$ & & \\
\hline G17 & 46 & & X & \\
\hline G18 & 46 & $X$ & & \\
\hline G19 & 41 & & $X$ & \\
\hline G20 & 32 & $X$ & & \\
\hline G21 & 43 & & $\mathrm{X}$ & \\
\hline G22 & 46 & & X & \\
\hline G23 & 55 & & $\mathrm{X}$ & \\
\hline G24 & 56 & & X & \\
\hline G25 & 45 & $X$ & & \\
\hline G26 & 36 & & & $X$ \\
\hline G27 & 47 & $X$ & & \\
\hline G28 & 38 & $X$ & & \\
\hline G29 & 44 & & $\mathrm{X}$ & \\
\hline
\end{tabular}




\section{Interview Guide and Response Sample}

Date: September 20, 2011

\begin{tabular}{|l|l|}
\hline School Survey No. & 01 \\
\hline Name of School & G01 \\
\hline County in District & \\
\hline Sub-County & \\
\hline Type of School & Government \\
\hline Number of Pupils & $556(292 / 264)^{\star}$ \\
\hline Number of Teachers & 8 \\
\hline
\end{tabular}

Name of Interviewee:

Position at School:

Contact:

WATER - data and questions concerning water collection and distribution

Water data collected

\begin{tabular}{|l|l|c|c|c|c|}
\hline $\begin{array}{l}\text { WATER DATA } \\
\text { and SOURCE }\end{array}$ & $\begin{array}{c}\text { Piped } \\
\text { Water }\end{array}$ & $\begin{array}{c}\text { Shallow } \\
\text { Well } \\
<30 \mathrm{ft}\end{array}$ & $\begin{array}{c}\text { Deep } \\
\text { borehole } \\
>30 \mathrm{ft}\end{array}$ & $\begin{array}{c}\text { Rainwater } \\
\text { Tank } \\
>6000 \mathrm{~L}\end{array}$ & $\begin{array}{c}\text { Spring/Pond } \\
\text { Open } \\
\text { Source }\end{array}$ \\
\hline Number of sources & & $2-3$ & & $\begin{array}{c}4 @ 10,000 \mathrm{~L} \\
\text { each }\end{array}$ & \\
\hline $\begin{array}{l}\text { Description of } \\
\text { source }\end{array}$ & & $\begin{array}{c}\text { Not } \\
\text { protected }\end{array}$ & & Plastic & \\
\hline $\begin{array}{l}\text { Other source } \\
\text { notes... }\end{array}$ & & $\begin{array}{c}\text { In } \\
\text { swampy }\end{array}$ & & $\begin{array}{c}\text { Don't last } \\
\text { thru dry } \\
\text { season }\end{array}$ & \\
\hline $\begin{array}{l}\text { Distance from } \\
\text { School (km) }\end{array}$ & & Bad in dry & & Good & \\
\hline Reliability? & & & & & \\
\hline
\end{tabular}




\begin{tabular}{|l|c|c|c|c|c|}
\hline (good/bad) & season & & & \\
\hline $\begin{array}{l}\text { Is the water clean? } \\
\text { (yes/no) }\end{array}$ & No & & Yes & \\
\hline Estimated water use per day (L) $=200 \mathrm{~L}$ & \\
\hline
\end{tabular}

\section{Water Questions}

1. Successes (what works)? Another water source is nearby, $1 \mathrm{~km}$, shallow well

2. Challenges School faces? Other source is bad, students get sick

3. Improvements that can be made? Protect sources like shallow wells, construction of boreholes, springs

SANITATION - data and questions concerning latrine use conditions and hygiene

\section{Latrine use data collected}

\begin{tabular}{|l|c|c|c|c|c|}
\hline LATRINE USE & $\begin{array}{c}\text { Simple } \\
\text { pit } \\
\text { latrine }\end{array}$ & $\begin{array}{c}\text { Ventilated } \\
\text { improved } \\
\text { pit latrine } \\
\text { (VIP) }\end{array}$ & $\begin{array}{c}\text { Composting } \\
\text { latrine } \\
\text { (wet or dry) }\end{array}$ & $\begin{array}{c}\text { Pour- } \\
\text { flush } \\
\text { toilets } \\
\text { (or } \\
\text { flush) }\end{array}$ & Other/None \\
\hline $\begin{array}{l}\text { Number of latrines } \\
\text { and stances }\end{array}$ & & $\begin{array}{c}2 \text { @5stances } \\
\text { each }\end{array}$ & & & \\
\hline $\begin{array}{l}\text { Total number of } \\
\text { stances }\end{array}$ & & 10 & & & \\
\hline $\begin{array}{l}\text { Separate for males } \\
\text { and females? } \\
\text { (yes/no) }\end{array}$ & & $\begin{array}{c}\text { Yes (1-girls, } \\
\text { 1-boys) }\end{array}$ & & & \\
\hline $\begin{array}{l}\text { Separate for } \\
\text { teachers and } \\
\text { students? (yes/no) }\end{array}$ & & $\begin{array}{c}\text { Yes } \\
\text { (1-stance) }\end{array}$ & & & \\
\hline
\end{tabular}




\begin{tabular}{|l|l|l|l|l|l|}
\hline $\begin{array}{l}\text { Latrine doors? } \\
\text { (yes/no) }\end{array}$ & Yes & & & \\
\hline $\begin{array}{l}\text { Clean/Conductive for } \\
\text { use? (yes/no) }\end{array}$ & Yes & & & \\
\hline Latrine pit covered? & No & & & \\
\hline $\begin{array}{l}\text { Water/Soap for } \\
\text { handwashing? }\end{array}$ & No & & \\
\hline Total number of students at the school = 556 & \\
\hline Pupil to latrine stance ratio = 56:1
\end{tabular}

\section{Sanitation Questions}

1. Successes (what works)? None answered (NA)

2. Challenges School faces? Not enough latrines or stances, emptying latrines is costly, scarcity of cleaning equipment

3. Improvements that can be made? More latrines are needed, talked about composting latrines 


\section{URCS Study Request Form}

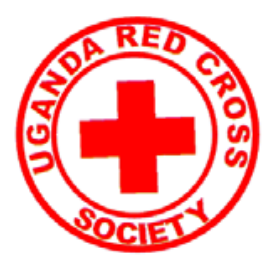

Uganda Red Cross Society

Rakai Branch

PO Box 195, Kyotera, Uganda

Email: urcsrakai@redcross.co.org Tel: +256(0)776312135

\section{Water and Sanitation Survey of Rakai District Primary Schools}

\section{SURVEY DESCRIPTION}

The 2011 Water and Sanitation Survey of Rakai District Primary Schools will be carried out by volunteers at the Uganda Red Cross Society, Rakai Branch, from September October of 2011. The purpose of the study is to discover the current conditions of water availability and access to sanitation among Rakai District primary schools. The following data collected will be used to help improve the School's planning, implementation, and management of all water and sanitation practices. Your school's help in collecting this data is greatly appreciated.

\section{WATER}

An important aspect of this study is to learn where and how Rakai District primary schools are collecting and distributing water. Questions concerning water availability, source type and description, distance from source, reliability of source, estimated water use per source, and other water needs will help establish a baseline understanding of 
what's working, what's not, and what can be done to improve each school's water availability and distribution.

\section{SANITATION}

Access to sanitation and a healthy learning environment is fundamental to students' health and academic performance. This study will look at what sanitation options are available at the School concerning latrine use, condition, and the promotion of improved hygiene practices. For each School, a pupil to stance ratio will be determined and the promotion of hand-washing among users will be stressed.

On behalf of the Uganda Red Cross Society, Rakai Branch, we thank you for help and interest in promoting Rakai Districts' Primary Schools' access to improved water and sanitation practices. Please feel free to contact us anytime with your suggestions, questions or concerns.

$-$

Colin M. Casey

Uganda Red Cross Society, Rakai Branch

US Peace Corps, Uganda, 2009-2011

Water and Sanitation Engineer

Email: cmcasey@mtu.edu, 


\title{
E. MTU IRB Research Consent Form
}

\author{
CONSENT TO PARTICIPATE IN RESEARCH \\ (IRB Exempt Approval M0812E)
}

\section{A Water and Sanitation Survey of Primary Schools in Rakai District, Uganda}

You are asked to participate in a research study conducted by Colin Casey from the United States Peace Corps and the Civil and Environmental Engineering Department at Michigan Technological University (MTU). Your participation in this study is entirely voluntary. Please read the information below and ask questions about anything you do not understand, before deciding whether or not to participate.

\section{Purpose of the Study}

The 2011 Water and Sanitation Survey of Primary Schools in Rakai District, Uganda will be carried out by volunteers Colin Casey and Ssembatya Joseph (interviewers) from the Uganda Red Cross Society, Rakai Branch. This study is being conducted at an estimated 60 primary schools, both private and government, throughout the District from September - October of 2011. The purpose of the study is to discover the current conditions of water availability and access to sanitation among District primary schools. After the study, an assessment will be made to highlight the successes, challenges, and improvements schools have made in regards to improved water and sanitation practices.

\section{Procedures}

Upon a visit to the School, the interviewers will meet with a director or teacher whom is knowledgeable about the water and sanitation conditions at the School. After obtaining consent, the interviewers will request your help to complete a water and sanitation survey where you will be asked to provide basic information about the school including, the number of students and teachers, the School's water availability, the School's 
latrines and their condition, and other hygiene practices. Following the completion of the survey, the interviewers will request to visit the School's water sources and latrines to obtain a photo record of the School's water and sanitation conditions.

\section{Potential Benefits}

This study will not bring you any immediate benefits other than giving you the opportunity to share your School's views and opinions. However, your participation will be of considerable value for educational purposes and in understanding what's working and what's not in regards to water and sanitation. The data collected will also be used to help improve the District's and local partner's knowledge, planning, implementation, and management of water and sanitation projects.

\section{Potential Risks}

This project is not intended to provoke any physical or emotional discomfort to you or the School. It also is not intended to retrieve sensitive or confidential information. However, in case you choose to share sensitive information during the interview all efforts will be made to ensure confidentiality. In the event of physical and/or mental injury resulting from participation in this research project, Michigan Technological University does not provide any medical, hospitalization, or other insurance for participants in this research study, nor will Michigan Technological University provide any medical treatment for any injury sustained as a result of participation in this research study, except as required by law.

\section{Confidentiality}

Any information that is obtained in connection with this study and that can be identified with you will remain confidential and will be disclosed only with your permission or as required by law. Confidentiality will be maintained by using eliminating the School's and interviewees name in the final report. 


\section{Participation and Withdrawal}

You can choose whether or not to be in this study. If you volunteer to be in this study, you may withdraw at any time without consequences of any kind of loss or benefits to which you are otherwise entitled. You may also refuse to answer any questions you do not want to answer.

\section{Identification of Investigators}

If you have any questions or concerns about this research, please contact the principal investigator, Dr. Kurt Paterson at (1-906) 487-3495 or email at paterson@mtu.edu. You may also contact Colin Casey at 256-702533609 or email at cmcasey@mtu.edu.

\section{Rights of Research Subjects}

The MTU Institutional Review Board has reviewed my request to conduct this project. If you have any concerns about your rights in this study, please contact Joanne Polzien of the MTU Office of Research Integrity and Compliance at (1-906) 487-2902 or email jpolzien@mtu.edu

I understand the procedure described above. My questions have been answered to my satisfaction, and I agree to participate in this study. I have been given a copy of this form.

Printed Name of Subject

Signature of Subject

Date

Signature of Witness

Date 


\section{E. Contact Information and Data}

For further analysis of data and questions concerning this study, please contact the author at the email address provided.

$--$

Colin M. Casey

Email: cmcasey@mtu.edu

Blog: http://colincasey.blogspot.com/ 